\title{
Impact of trim on added resistance of KRISO Container Ship (KCS) in head waves: An
} experimental and numerical study

\author{
Emil Shivachev $^{a}$, Mahdi Khorasanchi $^{b}$, Sandy Day ${ }^{a}$, Osman Turan $^{a}$
}

${ }^{a}$ Department of Naval Architecture, Ocean and Marine Engineering, University of Strathclyde, Glasgow, United Kingdom

b Department of Mechanical Engineering, Sharif University of Technology, Tehran, Iran

\begin{abstract}
In this study, added resistance and motion responses of KRISO Container Ship (KCS) were evaluated experimentally and numerically in six different trim angles. A series of towing tank experiments were performed for six different trim angles at design speed in calm water and regular head waves. The ship motions and added resistance were measured for several wavelength conditions considering short and long wave ranges with wave steepness of 1/60. Next, computations of the towed model in calm water and waves were performed using Unsteady Reynolds-Averaged Navier-Stokes (URANS) CFD and 3-D potential methods. Effects of trim angles on added resistance were analysed and results concerning the performance of the vessel at different trim angles were plotted. Experimental and numerical results for the heave and pitch motions and the added resistance were compared and URANS CFD simulation results showed good agreement with the experimental data for the ship in head waves. Also, the results were compared to those from potential theory and range of trim and wave conditions were identified for the application of rapid linear potential flow method.
\end{abstract}

Keywords: Added resistance, Trim angle, EFD, CFD, Potential flow

\section{Introduction}

Shipping has always been an essential activity worldwide to transport goods and people between countries. Merchant shipping became a vital component of the global trade as more than 80 per cent of the global trade is carried by sea (UNCTAD, 2017). Fuel costs account for a big portion of all operational costs and any savings in fuel consumption will have a significant impact on overall operational expenses. Fluctuating fuel prices over the years have been driving the ship owners and operators to be more efficient within the last decade. Competitive 
economic conditions such as high fuel prices and overcapacity of merchant shipping fleet push ship owners and operators to operate in a more efficient way. Furthermore, new environmental regulations and rules from international regulatory bodies such as International Maritime Organisation (IMO) drive the shipping industry to be more efficient in terms of fuel consumption. In 2014, IMO made amendments to MARPOL ANNEX IV and adopted new mandatory energy efficiency measures to reduce the greenhouse gas emissions from international shipping. These measures include Energy Efficiency Design Index (EEDI) for all new ships and Shipping Energy Management Plan (SEEMP) for all ships in operation. Recently, IMO adopted a new strategy stating its commitment to reduce the $\mathrm{CO}_{2}$ emissions of international shipping by $40 \%$ in 2030, aiming towards $70 \%$ reduction in 2050 compared to 2008 level which is the first long term plan to curb shipping emissions by IMO (IMO, 2019). Therefore, shipping companies are under increasing pressure to improve their ships' energy efficiency.

Energy efficiency of a ship can be determined by its design, hull and machinery condition and how the vessel is actually operated in terms of speed, draft and trim. Traditionally ship hulls are optimised for one speed and one draft. However, during a ships lifetime, it operates within a range of different speeds and drafts. Industrial switch to slow steaming over the past years can be an example of how inefficient is to optimise ships at level trim for one speed and one draft. Trim optimisation can be regarded as one of the easiest and cheapest methods among many fuel-saving measures recommended by IMO as it does not require any hull shape modification or engine upgrade (IMO, 2016a). Investigations from various parties have found that by sailing under optimal trim conditions, vessels can save by $2-5 \%$ on fuel costs, with a corresponding reduction in greenhouse gas emissions (ABS, 2014; IMO, 2016b). Many different companies such as classification societies, ship operators and vessel monitoring system providers offer trim optimisation solutions. Hence, it is already an attractive measure for ship owners. A market survey study conducted by HSH Nordbank (2013) with national and international shipping companies revealed that 71 per cent of the survey participants are using trim optimisation solutions for their ships.

Traditional way to understand the effect of trim on hull performance is to carry out systematic model tests in a towing tank. CFD simulations are also becoming popular in recent years to assess the optimum trim and to investigate the effect of different trim conditions. Larsen et al, (2011) carried out a broad trim optimization study which includes investigation of resistance and propulsive origin factors by conducting model tests, high fidelity CFD and potential theory 
CFD. Iakovatos et al (2014) conducted towing tank experiments for five different hull models in calm water and stated the importance of experimental investigation for trim optimisation studies. Lv et al (2013) used a 3D panel method to investigate the wave-making resistance of Wigley hull operating at different trims and identified optimum trim angle for lowest wavemaking resistance. Sun et al (2016) developed a trim optimization tool through use of CFD for resistance calculations and applied it on a real container ship to prove the benefits of trim optimization. Shivachev et al (2017) used both CFD and Experimental Fluid Dynamics (EFD) to investigate the influence of trim on ship resistance for KCS. Apart from EFD and CFD based studies, Decision Support Systems based on real-time measurements from the ship for fueloptimum trim have also been proven to result in considerable fuel savings for relatively low investment (Hansen and Freund, 2010). These tools generally use logged operational data to calculate the optimal trim. Bertram (2014) notes that these machine learning based systems may give good results but requires more training time and crew awareness. Overall, limited research have been performed to investigate the effects of trim on ship resistance.

Added resistance in waves is still a discussion topic within the marine research environment. Bertram (2016) discusses that there are no reasonably satisfactory methods available to predict the added power requirements in seaways at the present time. There are various methods which are being used. Model tests, numerical analysis, full-scale measurements and statistically derived design formulas are the main methods in this respect.

Model tests can be expensive and time-consuming due to waiting time between tests before the water is sufficiently calm enough for the next run. As it is necessary to build the physical model, towing tank experiments does not allow much flexibility for different design explorations in early design stages. Also scale effects are present for motions with strong viscous effects.

Computational methods have evolved for seakeeping analysis since the 1950s. Strip methods are the oldest and most popular approach for seakeeping analyses. Strip methods are able to calculate heave and pitch motions reasonably accurate for normal ships. There are two major techniques used to predict added resistance, namely the far-field method and the near-field method. The far field method is based on the momentum and energy conservation principles. It was first introduced by Maruo (1957) using the Kochin function which includes radiating and diffracting wave components. Joosen (1966) and Newman (1967) also applied this method to predict added resistance and wave drift of ships. Following this, Gerritsma and Beukelman (1972) introduced the radiated energy approach to predict added resistance in head seas which 
was widely used in strip theory codes due to its easy application. Salvesen (1978) confirmed the importance of accurate ship motion estimations to reliably predict added resistance in waves with the use of ship motions obtained from the strip theory method of Salvesen et al (1970). In the near field approach, the added resistance is predicted by integration of the hydrodynamic pressure on the wetted body surface. Many researchers used the near-field method to investigate the added resistance Faltinsen et al (1980), Joncquez et al (2008), Kim and Kim (2011). Blok, (1993) performed various experimental tests showing the origin of the added resistance and the contribution of the added resistance components. The author found that the added forces of resistance are applied mainly at the section of the bow. On the other hand, as computational power increased significantly and access to these computational facilities became more widely available over the years, CFD techniques based on the solution of Reynolds averaged Navier Stokes (RANS) have become a powerful tool to study ship motions and added resistance. Simonsen et al (2013) stated the importance of including effects of breaking waves, turbulence and viscosity in numerical methods, which are ignored in the potential theory approach. RANS methods are capable of doing this as viscous effects can directly be incorporated in their equations. Many studies demonstrated the ability of CFD methods against experimental studies. Sato et al (1999) carried out one of the early studies to predict the motions of the Wigley hull by using CFD simulations. Orihara and Miyata (2003) investigated added resistance and motions of S175 container ship with different bulbous bows using RANS method. As RANS method provided good results, more researchers used it to study different geometry and cases. Carrica et al (2007) studied the motions of a DTMB 5512 model in regular, small amplitude head waves. Castiglione et al. (2011) performed seakeeping analysis of a catamaran in waves with high wave amplitudes using URANS approach. Simonsen et al. (2013) investigated the added resistance, ship motions and wake flow field of KCS in regular head waves by using Experimental Fluid Dynamics (EFD) and CFD methods. Tezdogan et al. (2015) focused on predicting ship motions and added resistance of full scale KCS at design and slow steaming speeds by performing URANS simulations using Star $\mathrm{CCM}+$. Increase in effective power and fuel consumption due to added resistance was also calculated. Park et al (2016) investigated the added resistance of KVLCC2 tanker in head waves at different drafts by using EFD and potential theory methods. Kim et al. (2017) predicted the added resistance and ship motions of KVLCC2 at various speeds and wave steepnesses. Recently, Sigmund and el Moctar (2018) carried out an extensive study to investigate the added resistance and ship motions of four different ship types, which includes a cruise ship, a post-Panamax containership, a tanker, and Wigley hull, in short and long regular 
head waves and validated the results against experiments. Hizir et al. (2019) investigated the added resistance force components and non-linearity of added resistance and ship motions of KVLCC2 using CFD and 3-D potential flow methods.

To the best of our knowledge, the majority of trim related studies have been performed at calm water and many of the added resistance studies have been conducted at level trim angles. Optimum trim attained at calm water may not have the same effect in real sea environment as waves restrict overall ship behaviour and lead to speed loss. Therefore, added resistance in waves at different trim angles should be investigated in ship operational optimization to increase the energy efficiency. In that regard, this study aims to provide an understanding of the seakeeping behaviour and performance of the KCS model at different trim angles.

The present study employs EFD and CFD and potential theory based methods to investigate ship motions and added resistance in regular head waves at six different trim angles. Numerical computations of ship motions and added resistance were validated against model scale experiments.

\section{Experimental Setup}

All experiments in this study were carried out in the towing tank of the Kelvin Hydrodynamics Laboratory (KHL) at the University of Strathclyde. The tank is $76 \mathrm{~m}$ long, $4.6 \mathrm{~m}$ wide and has a depth of 2.5 meters. The tank is equipped with a four flap active absorbing wavemaker which is capable of generating regular waves of over $0.6 \mathrm{~m}$ in height and irregular waves of over $0.75 \mathrm{~m}$ in height. A beach of total length $13 \mathrm{~m}$ is installed at the opposite end of wavemaker for the absorption of the waves and reflection reduction. The towing tank features are schematically shown in Figure 1.

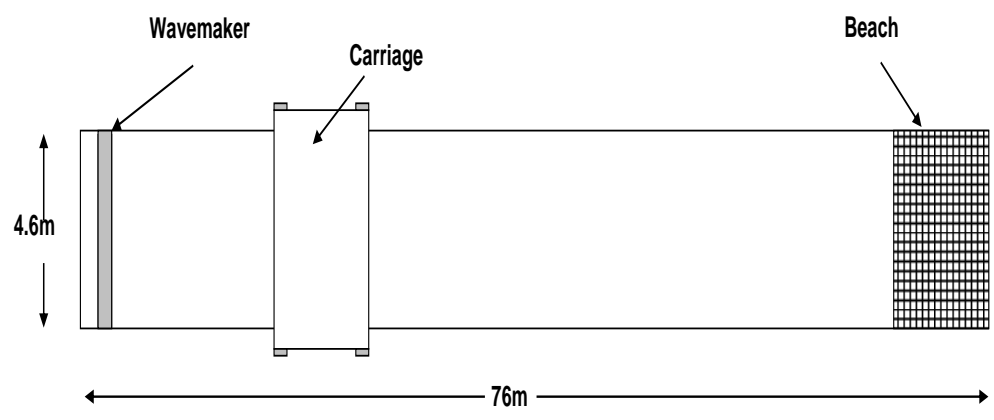

Figure 1 Kelvin Hydrodynamics laboratory 


\subsection{Description of the tested model}

A model of KCS was constructed with a scale factor of $1 / 75$. Model size was defined with respect to the dimensions of the towing tank. Principal dimensions of the full scale and model scale KCS are given in Table 1.

Table 1 Principal dimensions of the KCS model (SIMMAN, 2008)

\begin{tabular}{llll}
\hline Dimensions & Symbols & Full Scale & Model Scale \\
\hline Scale ratio & & 1.0 & 75.0 \\
\hline $\begin{array}{l}\text { Length between the } \\
\text { perpendiculars (m) }\end{array}$ & $L_{B P}$ & 230.0 & 3.0667 \\
\hline Beam at waterline (m) & $B_{W L}$ & 32.2 & 0.4293 \\
\hline Depth (m) & $D$ & 19.0 & 0.2533 \\
\hline Design draft (m) & $T$ & 10.8 & 0.144 \\
\hline Displacement (m $\left.{ }^{3}\right)$ & $\Delta$ & 52030 & 0.1203 \\
\hline $\begin{array}{l}\text { Wetted surface area without } \\
\text { rudder (m }{ }^{2} \text { ) }\end{array}$ & $S$ & 9530 & 1.675 \\
\hline $\begin{array}{l}\text { Longitudinal centre of gravity } \\
\text { from the aft peak (m) }\end{array}$ & $L C G$ & 111.6 & 1.49 \\
\hline Block coefficient & $C_{B}$ & 0.651 & 0.651 \\
\hline Moment of Inertia & $K_{y y} / L_{B P}$ & 0.25 & 0.25 \\
\hline $\begin{array}{l}\text { Design speed (m/s, full scale: } \\
\text { kn) }\end{array}$ & $U$ & 24 & 1.426 \\
\hline Froude number (based on $\left.\mathrm{L}_{B P}\right)$ & $F r$ & 0.26 & 0.26 \\
\hline
\end{tabular}

Tests were carried out for the bare hull without rudder and other appendages. Model was constructed of high density foam which was sanded to a smooth finish and then a coating was applied. The inside of the model consisted of a hollow box lined with wood which allowed various mass distribution inside the model to obtain different trim angles and required space for the location of the tow point. The towing point was located at the LCG of the model. Studs were installed on the bow and the bulb in order to trip the flow into becoming turbulent as can be seen in Figure 2. 


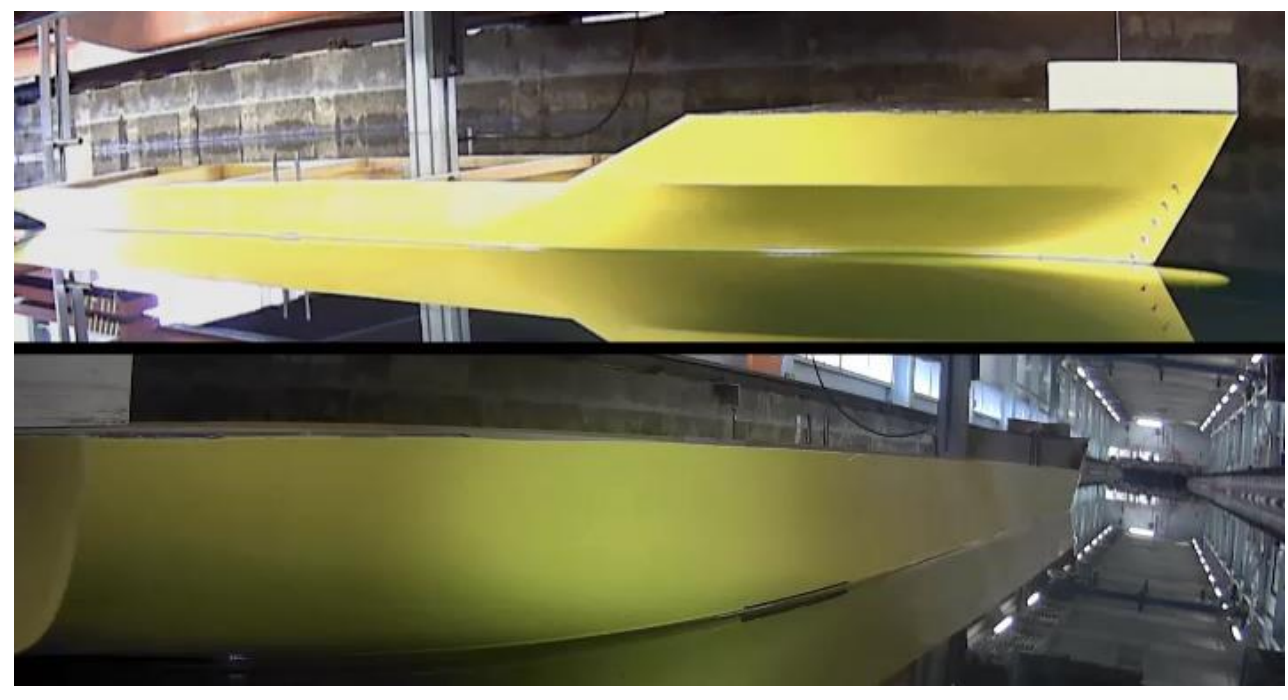

Figure 2 KCS Model attached to the carriage

Two Linear Variable Differential Transformers (LVDT) were employed to measure trim and sinkage. First LVDT was located on the tow post and measured the vertical displacement of the model at this point i.e. the sinkage. Second LVDT was located at the bow of the model and recorded the vertical displacement of the bow i.e. trim. A load cell was located at the point by which the model is towed and therefore measured the force required to tow the vessel. Wave probes were located in the middle of the tank and one ultrasonic wave probe close to the model. All measuring devices were calibrated before conducting the tests. The experimental setup is schematically shown in Figure 3.

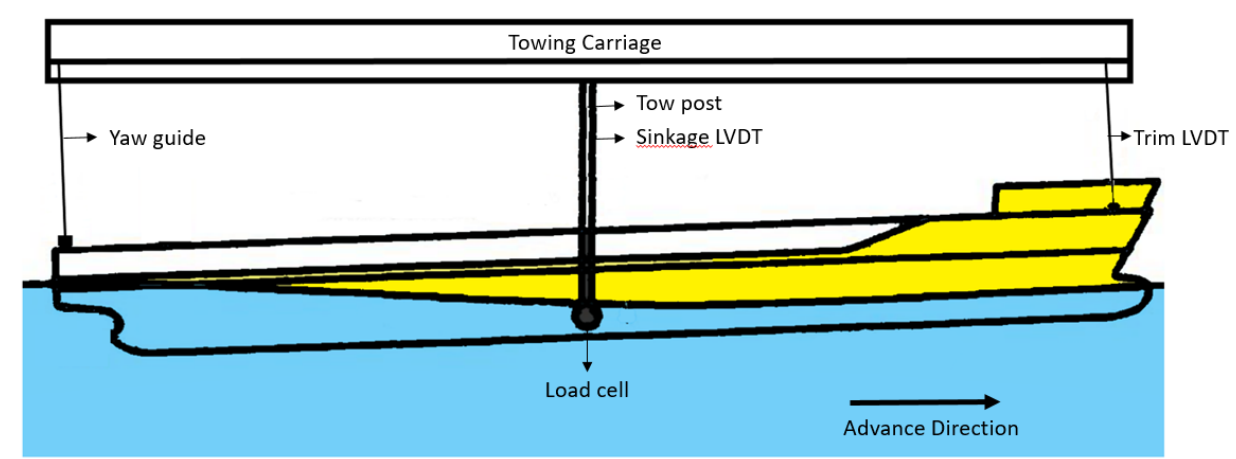

Figure 3 Experimental setup

All tests were carried out in fresh water and water temperature was recorded regularly during the tests. Model resistance, dynamic trim and sinkage, bow motions, wave amplitude and actual speed of the model were recorded during the runs. The model was only allowed to heave and pitch while other motions were restricted. 
Seven different regular head waves were carefully selected covering the wave-ship length ratio $\lambda / \mathrm{L}=0.5,0.65,0.75,0.85,1.15,1.37,1.95$ with wave steepness of $\mathrm{H} / \lambda=1 / 60$, as shown in Table 2.

Table 2 Test matrix

\begin{tabular}{ccccc}
\hline $\boldsymbol{\lambda} / \mathbf{L}$ & Wavelength (m) & Wave height $(\mathbf{m})$ & $\begin{array}{l}\text { Wave } \\
\text { amplitude (m) }\end{array}$ & Wave steepness \\
\hline $\mathbf{0 . 5}$ & 1.533 & 0.0256 & 0.0128 & $1 / 60$ \\
\hline $\mathbf{0 . 6 5}$ & 1.993 & 0.0332 & 0.0166 & $1 / 60$ \\
\hline $\mathbf{0 . 7 5}$ & 2.300 & 0.0383 & 0.0192 & $1 / 60$ \\
\hline $\mathbf{0 . 8 5}$ & 2.607 & 0.0434 & 0.0217 & $1 / 60$ \\
\hline $\mathbf{1 . 1 5}$ & 3.527 & 0.0588 & 0.0294 & $1 / 60$ \\
\hline $\mathbf{1 . 3 7}$ & 4.201 & 0.0700 & 0.0350 & $1 / 60$ \\
\hline $\mathbf{1 . 9 5}$ & 5.980 & 0.0997 & 0.0498 & $1 / 60$ \\
\hline
\end{tabular}

Tests were conducted for three different trim angles by bow, three for aft trim in total six different trim angles and level trim condition at design speed. Selected trim angle values range from 0.25 degree up to 1 degree for bow and stern trim conditions to cover a wide range of trim conditions and to ensure complete propeller immersion. These angles correspond to $1 \mathrm{~m}$ to $4 \mathrm{~m}$ trim in full scale.

\section{Numerical investigation}

This section aims to provide a brief overview about the main features of the adopted numerical approaches.

3-D linear potential theory results are obtained using PRECAL code, which is developed by the MARIN Cooperative Research Ships (CRS) and includes a 3-dimensional potential code (Van't Veer, 2009). The planar panel method, which is able to calculate the seakeeping performance of different hull forms such as monohulls, catamarans and trimarans, is adopted in PRECAL code. Since panel codes use a more detailed description of the hull, the diffracted and radiated waves can be accounted for in all directions. Furthermore, it has the capacity to calculate the deformation modes of a ship's hull girder, internal loads, pressure on the hull and added resistance in waves. Near-field approach based on direct pressure integration over the mean wetted hull surface is used for added resistance calculations. Only the mean values of forces and moments are taken into account in added resistance calculations. Calculations take only a short period of time since all computer cores are being used. Kim et al. (2017) and Hizir et al. (2019) have explained the code in more detail and they have presented results regarding 
the robustness of the code and provided a more detailed discussion of added resistance components.

URANS CFD simulations were carried out using commercial software Simcenter STAR$\mathrm{CCM}+$. For incompressible flows without external body forces, the averaged equations of continuity and momentum are expressed in tensor form in the Cartesian coordinate system as follows by Eq. (1) and Eq. (2) (Ferziger and Peric, 2002)

$$
\begin{aligned}
& \frac{\partial\left(\rho \bar{u}_{i}\right)}{\partial x_{i}}=0 \\
& \frac{\partial\left(\rho \bar{u}_{i}\right)}{\partial t}+\frac{\partial}{\partial x_{j}}\left(\rho \bar{u}_{i} \bar{u}_{j}+\rho \overline{u_{i}^{\prime} u_{j}^{\prime}}\right)=-\frac{\partial \bar{p}}{\partial x_{i}}+\frac{\partial \bar{\tau}_{i j}}{\partial x_{j}}
\end{aligned}
$$

in which $\overline{u_{i}}$ is the averaged velocity vector of fluid, $\overline{u_{i}^{\prime} u_{j}^{\prime}}$ is the Reynolds stresses, $\bar{p}$ is the mean pressure and $\bar{\tau}_{i j}$ is the mean shear stress tensor which is expressed as Eq. (3)

$$
\bar{\tau}_{i j}=\mu\left(\frac{\partial \overline{u_{i}}}{\partial x_{j}}+\frac{\partial \overline{u_{j}}}{\partial x_{i}}\right)
$$

where $\mu$ is the dynamic viscosity.

A second-order upwind scheme is used for discretization of convection and diffusion terms in the RANS equations. The semi-implicit method for pressure-linked equations (SIMPLE) algorithm is implemented in STAR-CCM+ to resolve the pressure-velocity coupling. Standard k- $\varepsilon$ turbulence model was chosen following many other studies such as Enger et al. (2010) and Tezdogan et al. (2015). This model is a two-equation model which introduces two additional equations to solve; one for the kinetic energy $(\mathrm{k})$ and one for the dissipation $(\varepsilon)$. According to SIEMENS Star CCM+ user guide the $\mathrm{k}-\varepsilon$ model is described as providing a good balance between robustness, computational cost and accuracy.

In order to simulate a floating ship at the free water surface, multiphase flow needs to be modelled. Free surface was captured by volume of fluid (VOF) method which has been proven as a suitable approach for flow involving hull shape and breaking waves (Muzaferija and Peric, 1999).

The ship was allowed to move freely in the pitch and heave directions with two degrees of freedom in the simulations, the same as in experiments. Dynamic Fluid Body Interaction (DFBI) model was employed in order to simulate the realistic ship motions. In DFBI model, the motion of the ship is simulated according to the acting forces induced by the flow. 


\subsection{Boundary Conditions}

The initial conditions and boundary conditions are defined to represent the KCS ship being towed in deep water. Selection of the boundary conditions and positioning of these boundaries are essential to obtain an accurate solution. A velocity inlet boundary condition was positioned at $1.5 \mathrm{~L}_{\mathrm{BP}}$ ahead of vessel to decrease the free running length of incident waves and a pressure outlet was selected at $3 \mathrm{~L}_{\mathrm{BP}}$ behind to avoid wave reflections. Velocity inlet boundary condition was also applied to top, side and bottom boundaries to prevent fluid reflections. A symmetry boundary condition was used to reduce the number of cells and computational cost. These boundary conditions were selected by following best practices for similar simulations as recommended by Simcenter and ITTC guidelines (SIEMENS, 2017). Artificial wave damping was applied at the outlet boundary to numerically reduce the wave amplitude. Figure 4 displays an overview of the computational domain showing KCS model and selected boundary conditions.

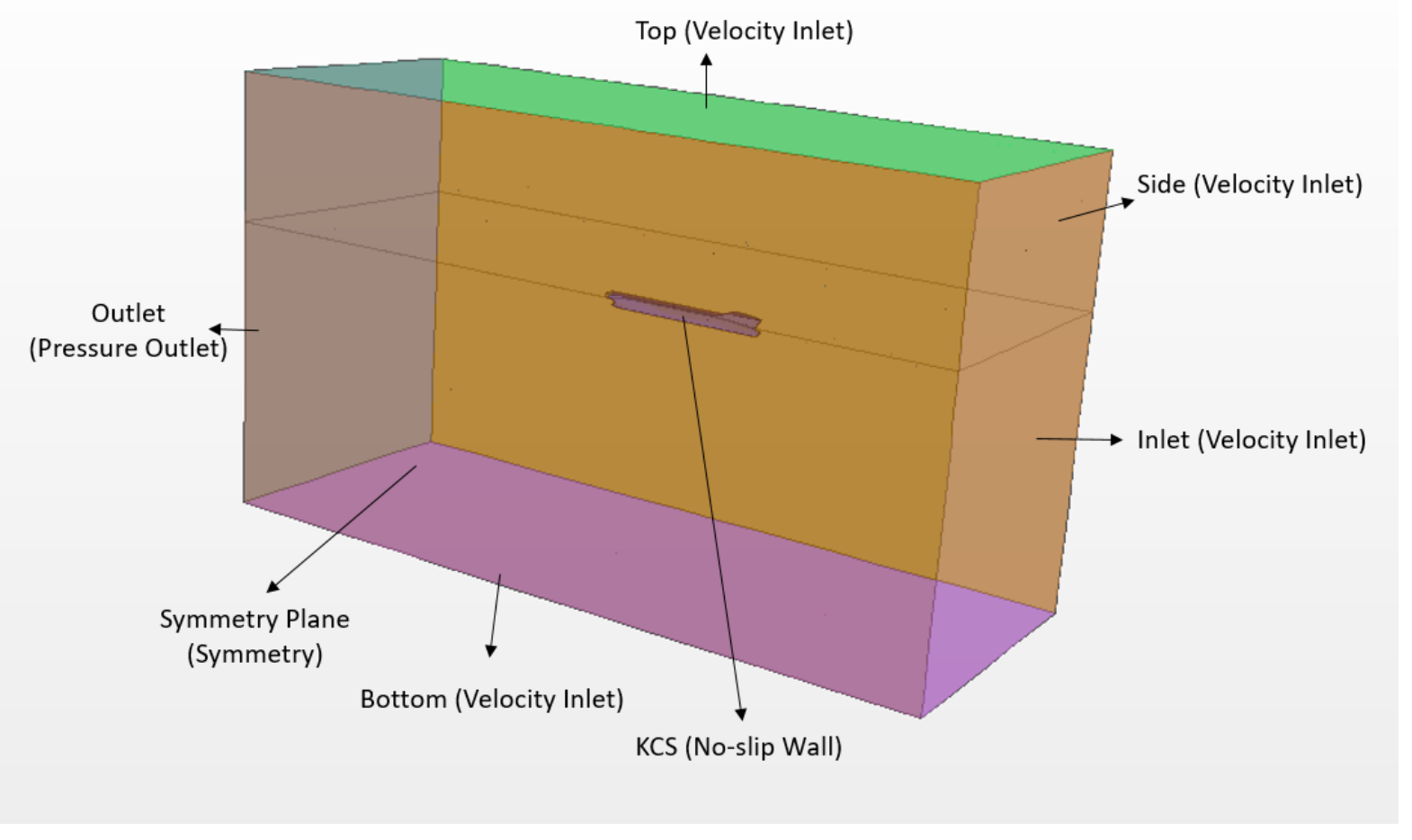

Figure 4 Overview of the computational domain and boundary conditions

The size of the computational domain and positions of boundary conditions are summarized in Table 3. 
Table 3 Locations of the boundaries in computational domain

\begin{tabular}{l|lll}
\hline Boundary & Position & Boundary Condition & Note \\
\hline Inlet & $2.5 \mathrm{~L}_{\mathrm{BP}}$ & Velocity Inlet & Aft Peak is set to 0 \\
Outlet & $3.0 \mathrm{~L}_{\mathrm{BP}}$ & Pressure Outlet & Aft Peak is set to 0 \\
Symmetry & - & Symmetry & Centre line is set to 0 \\
Side & $2.0 \mathrm{~L}_{\mathrm{BP}}$ & Velocity Inlet & Centre line is set to 0 \\
Top & $1.5 \mathrm{~L}_{\mathrm{BP}}$ & Velocity Inlet & Free surface is set to 0 \\
Bottom & $2.5 \mathrm{~L}_{\mathrm{BP}}$ & Velocity Inlet & Free surface is set to 0 \\
\hline
\end{tabular}

\subsection{Mesh Generation}

Volume mesh generation is crucial as it has a direct influence on accuracy of fluid flow simulations. Mesh construction defines the rate of convergence and it also has a strong influence on the accuracy of the final solution. Volume mesh was created by using the automatic meshing tool in Star CCM+. Trimmed cell mesher technique was employed as it provides robust and computationally efficient solution for complex meshing problems. Only half of the flow domain was simulated due to the lateral symmetry condition in order to reduce computational effort. Local mesh refinements were applied in the areas of interest such as the area nearby the ship hull, bulbous bow and stern, expected free surface and in the wake field that was created by the ship, in order to capture the complex flow features. The computations were performed at the same scale and same conditions as in the physical tests to ensure the best comparability.

Accurate resolution of the wave shape is one of the main goals in seakeeping simulations. It is necessary to create a good mesh which is refined in the correct regions. According to Star $\mathrm{CCM}+$ user guide, a minimum of 80 cells per wave length and 20 cells per wave height should be used on the free surface in order to resolve the wave shape. (SIEMENS, 2017). Based on these recommendations, base mesh system was created for seakeeping simulations. Cross sections of the volume mesh are presented in Figure 5. 


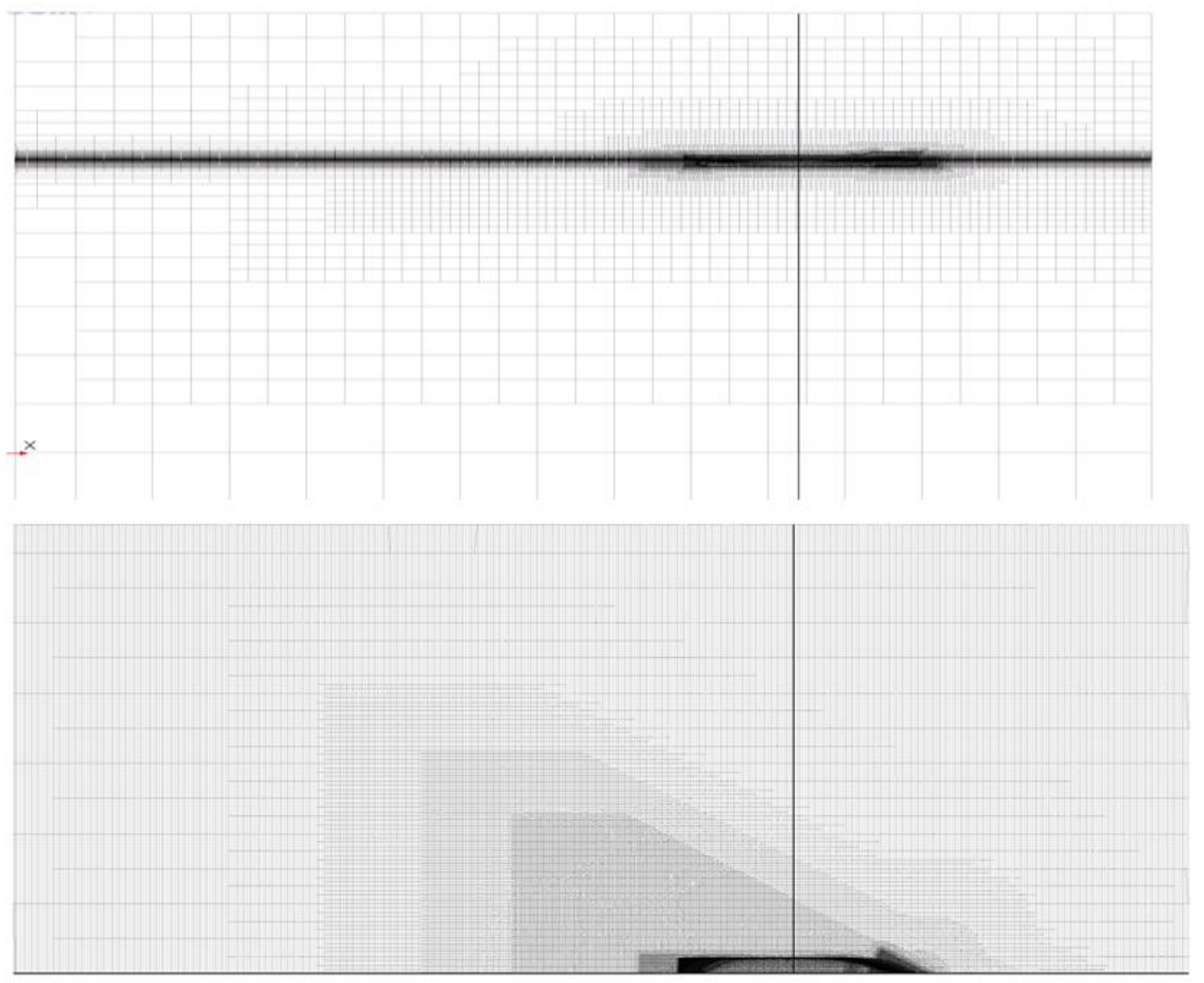

Figure 5 Computational mesh around the hull Profile view and Top view

The boundary layer was modelled using "All Y+ wall treatment" method in Star CCM+. Prism layers were placed near boundary walls along the hull surface in order to resolve the boundary layer accurately and to achieve the desired wall $\mathrm{Y}+$ values. It is important to keep the dimensionless wall distance $\mathrm{Y}+$ value within the range of boundary layer treatment. The aim should be to have either $\mathrm{Y}+<5$ or $30<\mathrm{Y}+<50$. The all-Y+ wall treatment should give results within this range. As shown in Figure 6, it was kept around a value of 45 at the underwater hull for each mesh size. This value can be considered as an appropriate size for the standard k- $\varepsilon$ model with all Y+boundary treatment.

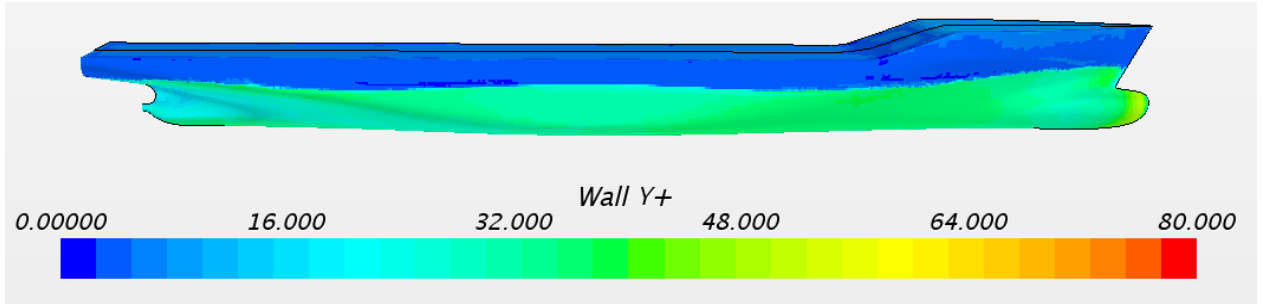

Figure $6 \mathrm{Wall}^{+}$on the underwater hull 


\subsection{Choice of time step}

It is essential to use an appropriate time-step size when simulating waves as cell size and time step size go hand in hand to resolve the wave shape. The time step used in the simulations is determined by ITTC guidelines and Courant number. Courant number is defined as the ratio of physical time step to the mesh size and it should be less than 1 for numerical stability. It is advised to use at least 100 time steps per encounter period. Therefore, time step size was adapted to simulated wave condition. It should be noted that a second-order temporal scheme was applied to discretise the unsteady term in the Navier-Stokes equations as first order can be too dissipative. (SIEMENS, 2017)

\section{Post Processing}

This section explains the post-processing procedure of the obtained results.

Measured and computed values of resistance amplitudes were normalised by using nondimensional total resistance coefficient $\mathrm{C}_{T}$ both in calm water and waves at different trim angles.

For calm water conditions $\mathrm{C}_{T}$ is calculated by:

$$
C_{T}=\frac{F_{X}}{\frac{1}{2} \rho U^{2} S}
$$

where $F_{X}$ is the time averaged longitudinal force (the total drag), $\rho$ is water density, $U$ is ship speed and $S$ is the wetted surface area of the ship in calm water.

In order to find the added wave resistance, calm water resistance (Fx,calm) is subtracted from the time averaged longitudinal force in waves $(F x$, wave $)$ for the same trim angle and speed. It was then normalized as follows:

$$
C_{A W}=\frac{(F x, \text { wave }-F x, \text { calm })}{\rho g \zeta_{I 1}^{2} B_{W L}^{2} / L_{B P}}
$$

Typical sample of computed longitudinal force time history is shown in Figure 7. In this figure oscillating solid red line represents the total resistance in waves, blue line time-averaged value of total resistance in waves and green line calm water resistance values. 


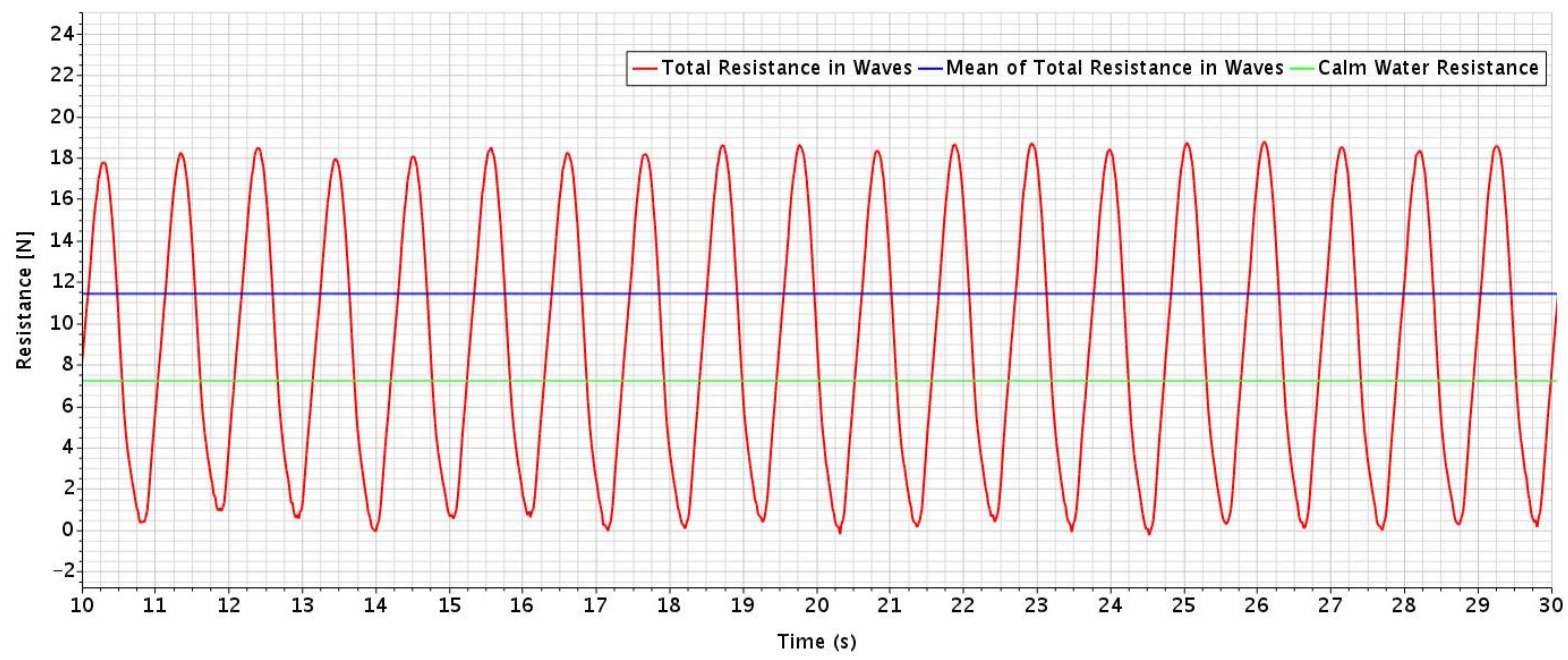

Figure 7 Time history of total resistance in waves and mean values of total resistance

It should be noted that Fourier Series analysis were performed to obtain the force and ship motions for the selected time history range.

As added wave resistance is proportional to the square of the wave amplitude, accuracy of used wave amplitude is of critical importance. Therefore, it is necessary to note that actual measured wave amplitude values were used instead of target values. Wave amplitudes were measured in both experiments and simulations. Figure 8 shows time history of simulated and measured wave profile at the wave probe for wave length $\lambda / \mathrm{L}=0.75$.

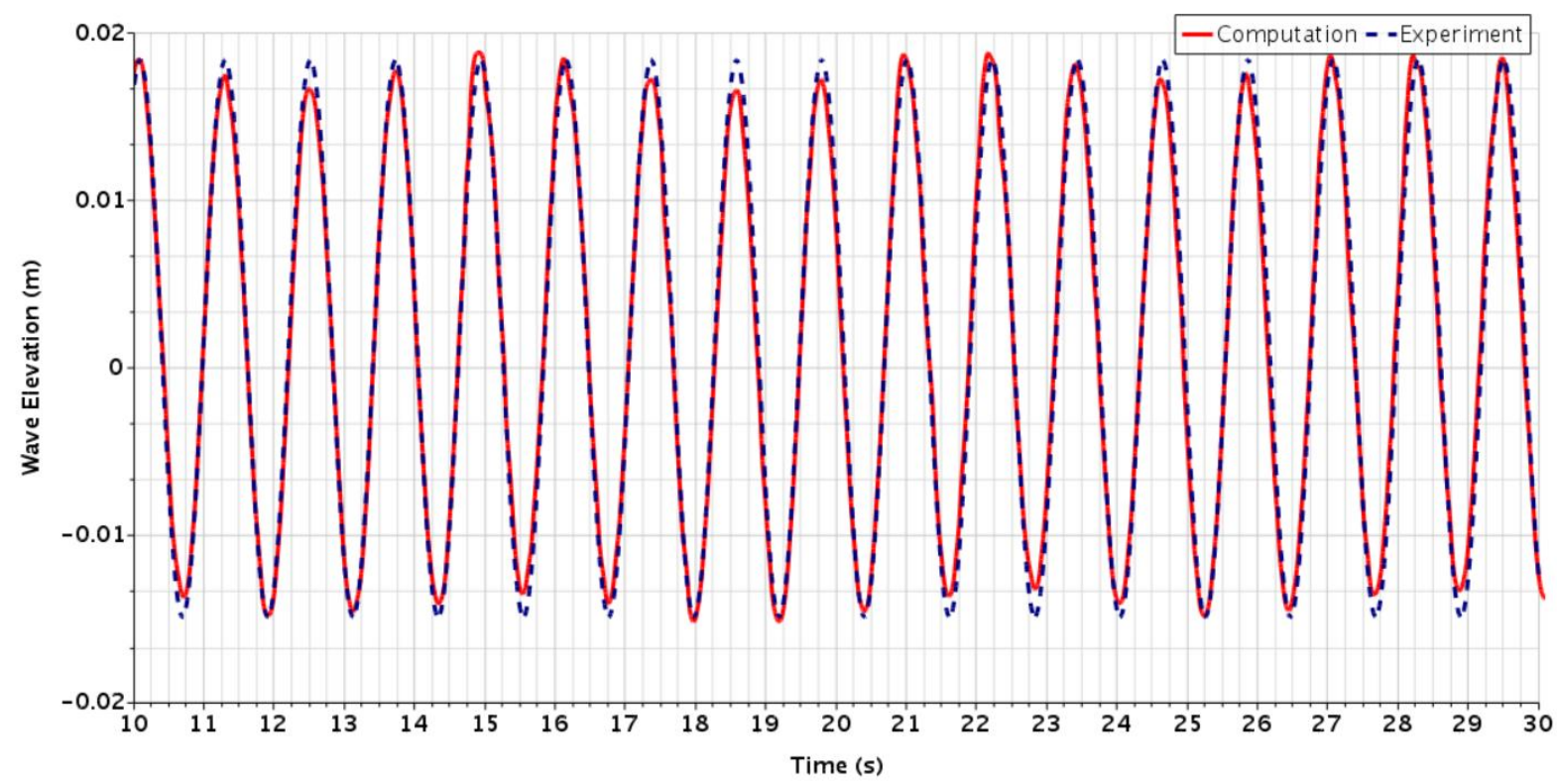

Figure 8 Computed and measured wave profile at the wave probe for $\lambda / \mathrm{L}=0.75$

The ship motions in waves were quantitatively analysed with the use of transfer functions. The definition of heave and pitch transfer functions, respectively, are given by:

$T F_{3}=\frac{x_{31}}{\zeta_{I 1}}$ 
$T F_{5}=\frac{x_{51}}{k \zeta_{I 1}}$

where $x_{31}, x_{51}$ are the first Fourier Series first order harmonic amplitudes of heave and pitch, $\zeta_{\mathrm{I} 1}$ is the incident wave amplitude and $k=2 \pi / \lambda$ is the wave number. Computed and measured heave and pitch motion time histories at $\lambda / \mathrm{L}=1.95$ are shown in Figure 9. The solid line indicates computed motions; while the dotted line shows measured motions from the experiments. Experimental data and numerical data show good agreement.
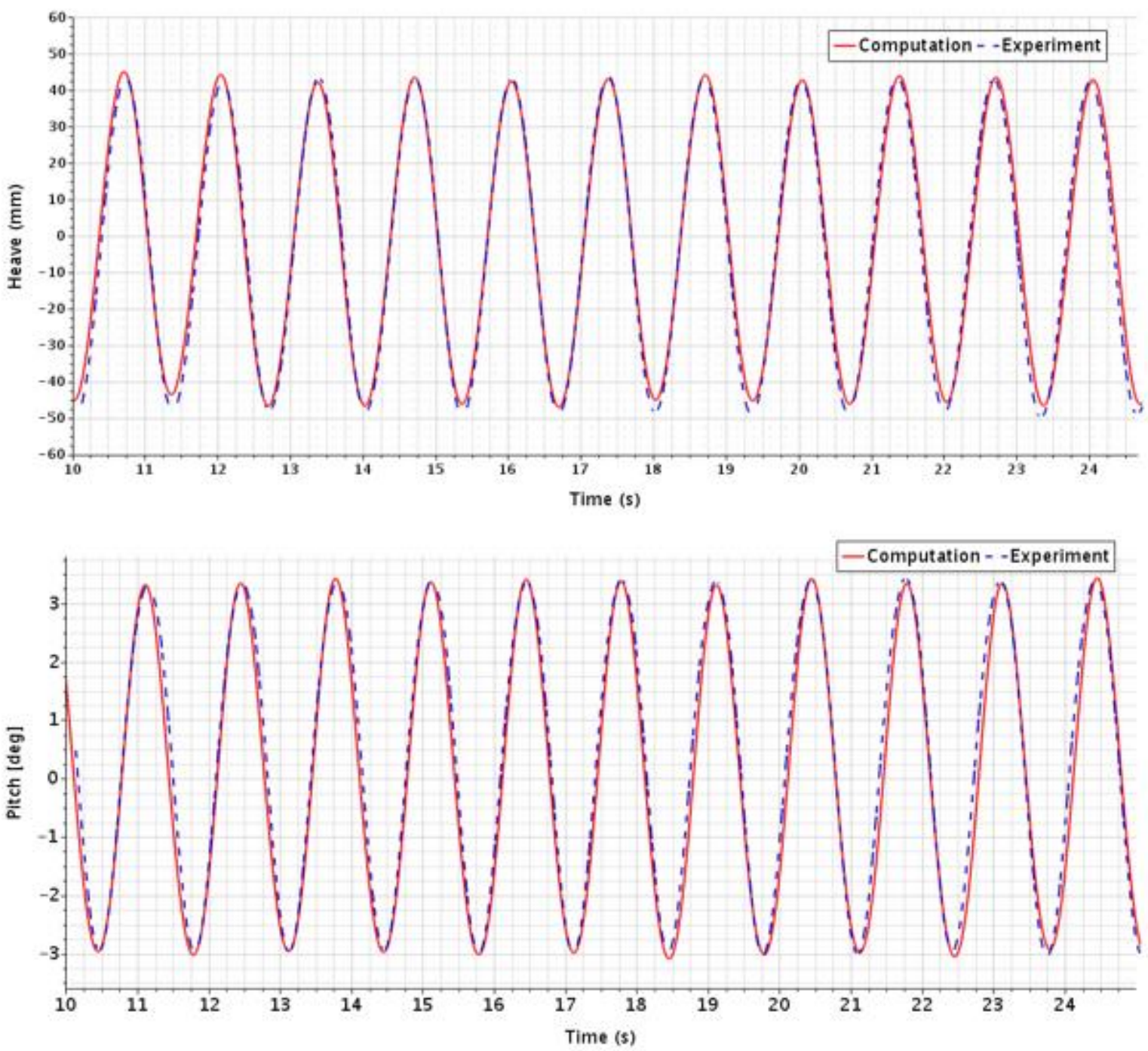

Figure 9 Computed and measured heave and pitch motion time histories at $\lambda / L=1.95$

\section{Results and Discussion}

In this section, experimental and numerical results are presented. Simulation results from CFD and 3D Potential flow methods are later discussed and compared against experimental findings. 


\subsection{Experimental Results}

In this section, experimental results are discussed to investigate the effects of trim on motion responses and added resistance of the vessel.

\subsubsection{Effects of Trim on Calm Water Resistance}

In order to investigate the influence of waves on optimum trim, first the calm water resistance for each specific trim angle is measured. Percentage differences of total resistance coefficient for different trim angles are calculated against level trim condition and presented in Figure 10.

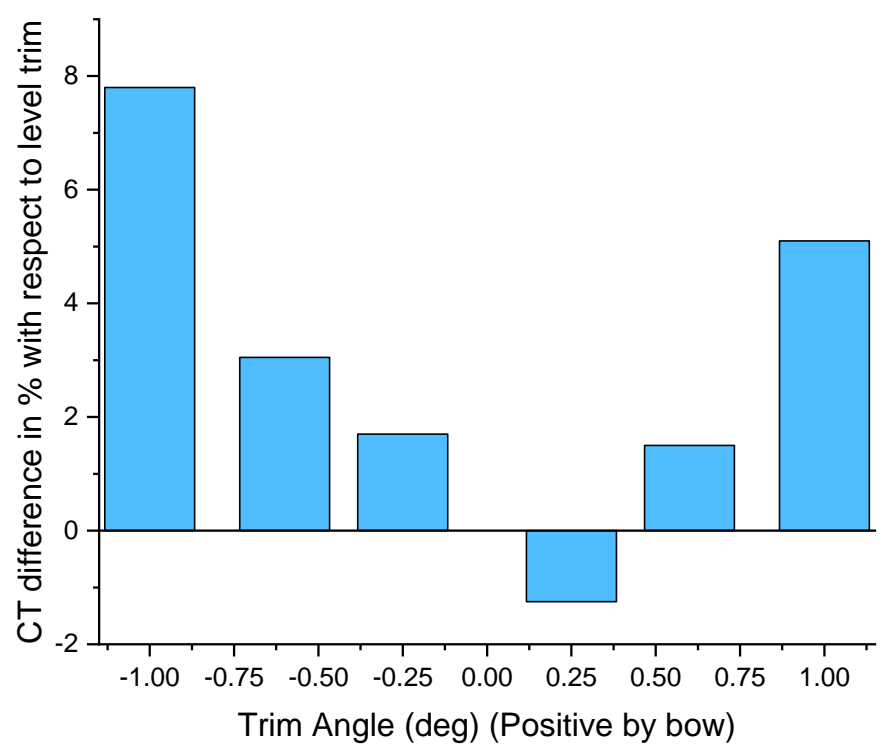

Figure 10 Comparison of calm water resistance at different trim angles

Trim by stern increases the total resistance of the ship for all investigated angles. 1 degree trim by stern causes the biggest increase with approximately 8 per cent compared to level trim. This significant increase can be explained by submergence of transom and increased water line length. Trim by stern causes also the bulbous bow to emerge above the free surface and thus creates unfavourable bow wave which leads to an increase in ships resistance. On the other hand, trimming the vessel slightly by bow ( 0.25 degrees $)$ performs best and provides 1.25 per cent reduction in total resistance at calm water conditions. Small reduction in wetted surface area and improved bulb performance may be the reason behind this reduction. However, trimming the vessel further by bow at larger angles of 0.6 and 1 degrees increase the total resistance with respect to level trim by $1.3 \%$ and $5 \%$ respectively at the design speed. This can be due to formation of higher bow wave at larger trim angles. Parts of the trim influence on calm water resistance study was published by Shivachev et al (2017). 


\subsubsection{Effects of Trim on Motion Responses}

In order to investigate the motion response of the ship at different trim angles results of the experimental and numerical study are discussed in this section.

Accurate prediction of ship motions are important as the added resistance is dominated by radiation in moderate to long wave range. Motions responses for each trim angle and operating at level trim are calculated and comparative response amplitude operators (RAOs) of heave and pitch motions obtained from the experiments at different trim angles are shown in Figure 11 and Figure 12 respectively. 

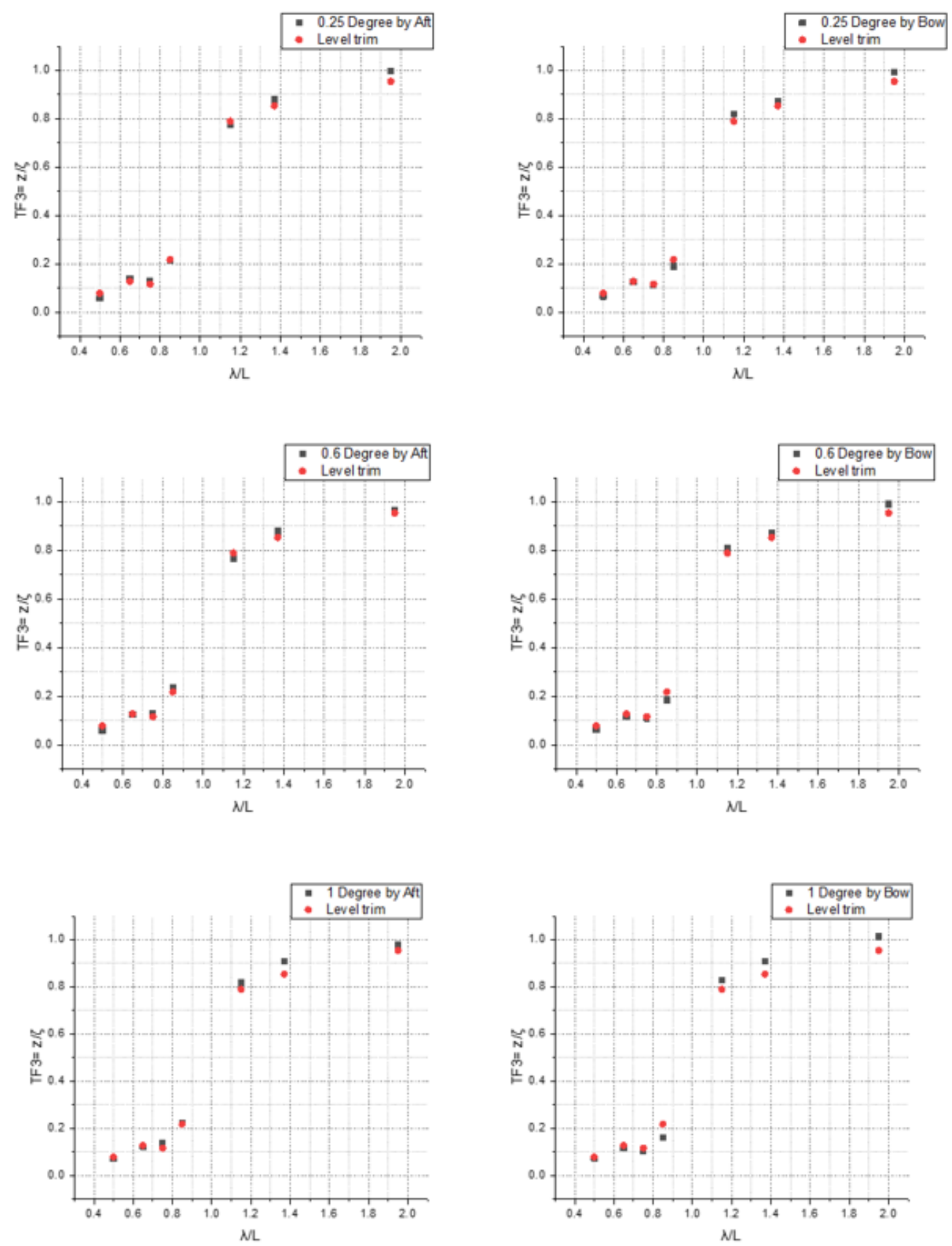

Figure 11 RAOs of Heave Motion 

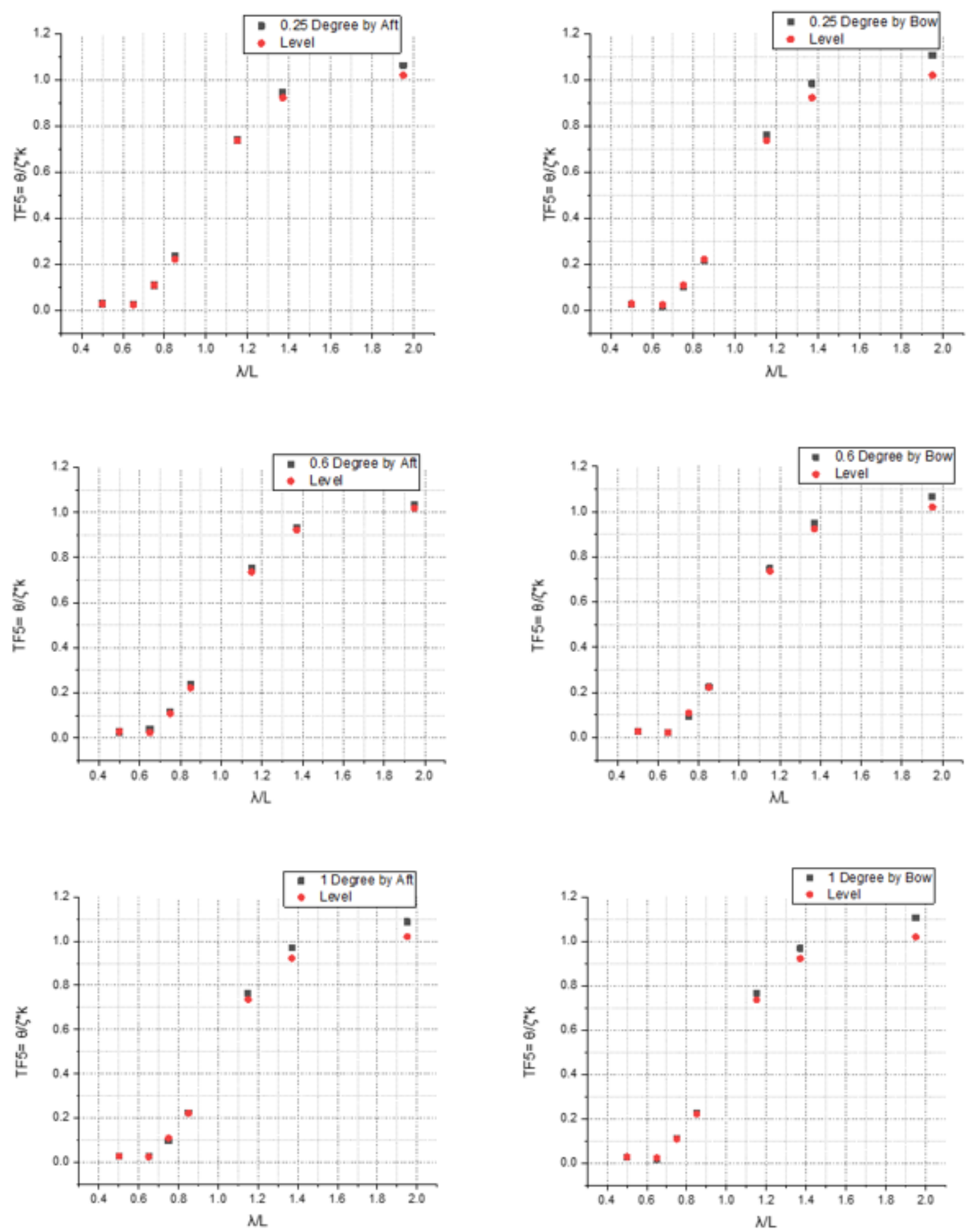

Figure 12 RAOs of Pitch Motion 
The results show that operating at different trim angles have little influence on ship motions and that trend of ship motions are similar to operating at level trim especially in short wave region. The motions are very small for the short waves which covers $\lambda / L=0.5 \sim 0.75$ as the wave radiation force is not dominant in this range and there is low energy which is not enough to oscillate the vessel. For all trim angles, heave and pitch motion responses had a higher value at long wave range $(\lambda / \mathrm{L}>1.15)$ at trimmed condition. Operating at level trim have slightly smaller pitch and heave response value at all wave conditions. Small trim angle of 0.25 degrees have no significant influence on motion responses. Heave response amplitudes decrease slightly at aft trim conditions at around the resonance period $(1.0<\lambda / \mathrm{L}<1.4)$ while pitch amplitudes vary insignificantly. At larger trim angles, motion responses increase slightly in long wave region. Maximum motion responses appear in the long wave region for all trim angles. As discussed by Lewis (1988), since the magnitude of the excitation force and the coefficient of motion equations are frequency functions, maximum responses may occur at long wavelength region rather than at the natural frequency.

\subsubsection{Effects of Trim on Added Resistance in waves}

Changes in added resistance at various trim angles are discussed in this section. Added resistance at trim by aft and trim by bow conditions are compared against level trim and results of experimental study are plotted in Figure 13.
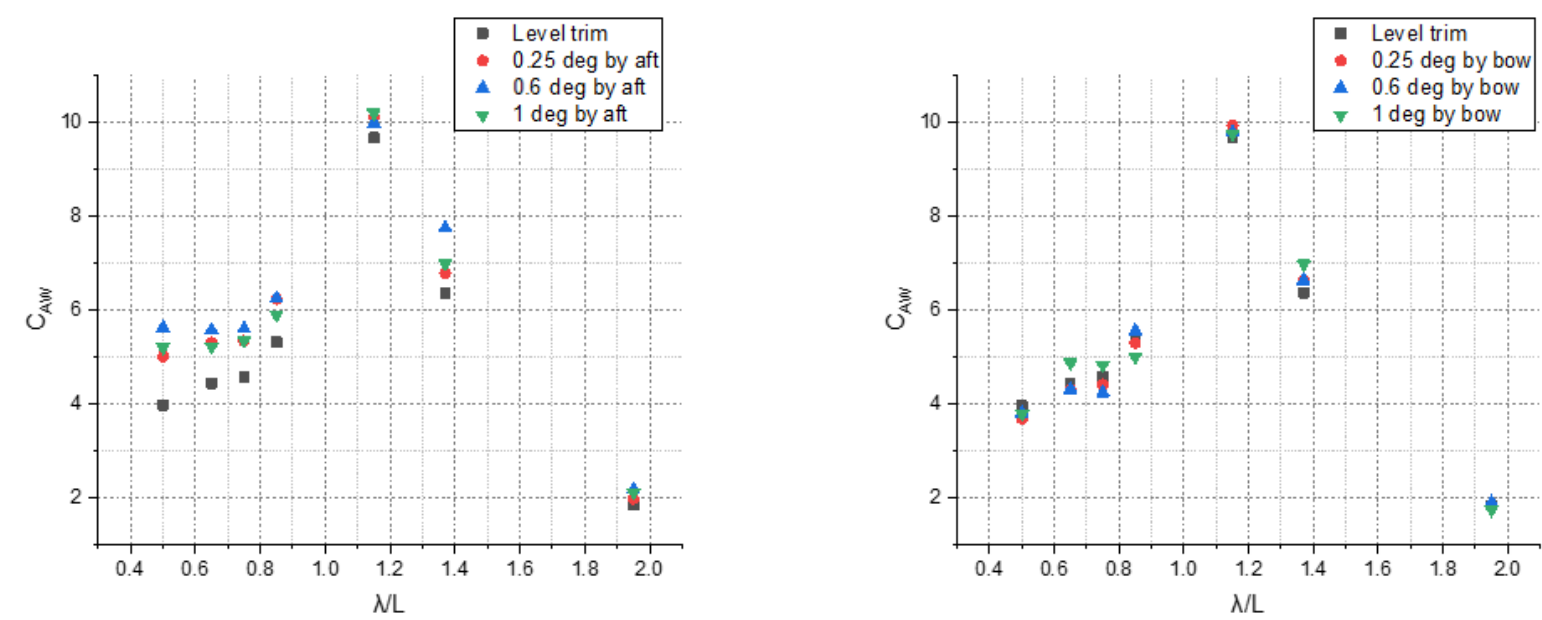

Figure 13 Added resistance comparisons at different trim angles

In short wave region, optimum trim trends are similar to calm water results as slight trim by bow results in the lowest added resistance value. The magnitude of savings are more significant compared to calm water results as 0.25 degree trim by bow can provide $7 \%$ reduction in added resistance coefficient compared to $1.25 \%$ reduction in calm water resistance coefficient. The added resistance in trim by aft conditions showed an increase in the short wave region which 
is in line with calm water predictions. However, losses amplitude is much larger at around 20\% in short waves compared $8 \%$ in calm water. In the short wave region, the diffraction component is dominant which is effected by the shape of the bow. Wave reflection creates significant amount of added resistance in short waves. A blunt bulbous bow has typically very large wave reflection and the effective shape of the bow changes with trim angle. The large wave reflection creates larger wave added resistance impact on the ship bow. Hence, the added resistance due to wave reflection effects are significant for trim optimisation studies. It can be said that the changes in the bow shape can be considered as a contributing factor to the added resistance in short wave region for trim by aft conditions. Trimming the ship 0.6 degree by aft results in highest added resistance in this region as motions are slightly higher compared to 1 degree trim by aft. Stern immersion at 1 degree trim by aft might be a reason for slightly reduced heave motions.

In moderate wavelength region, added resistance value reached its maximum when the wavelength was similar to the ship length $(\lambda / L=1.15)$. In moderate-long wave range added resistance is dominated by radiation which is related to the relative motion as mentioned earlier. Therefore, the increase in added resistance coefficient at trimmed conditions is line with the increase in relative motions in this wavelength region.

\subsection{Numerical Results}

In this section, computational results will be compared to experimental results and prediction capabilities of CFD methods at different trim angles will be discussed.

\subsubsection{Grid Convergence Study}

In order to investigate the numerical simulation uncertainty on wave added resistance and ship motions, grid uncertainty analysis also conducted using Grid Convergence Index (GCI) method of Roache (1998). The resonant case $(\lambda / L=1.15)$ wave condition was selected for grid convergence study as large motions and accelerations are likely to cause higher numerical errors (Weymouth et al. 2005). Computational mesh were refined by multiplying the mesh base size by $\sqrt{ } 1.7$ in all directions as this value provides sufficiently high refinement ratio for grid convergence studies. Three different mesh systems namely, a coarse, medium and a fine mesh comprising from $1.2 \mathrm{M}$ to $5.4 \mathrm{M}$ control volumes were created. The non-dimensional wall distance $\mathrm{Y}+$ on underwater hull was kept constant at a value of approximately 45 in order to minimize the effect of turbulence modelling and wall functions. 
In order to assess the grid convergence, the convergence ratio is used as written in Eq. (8) below:

$R=\varepsilon_{21} / \varepsilon_{32}$

In Eq. (8) $\varepsilon_{21}=\mathrm{S}_{2}-\mathrm{S}_{1}$ and $\varepsilon_{32}=\mathrm{S}_{3}-\mathrm{S}_{2}$ are the differences between medium-fine and coarse-medium solutions, where $S_{1}, S_{2}, S_{3}$ correspond to the solutions of fine, medium, and coarse grid systems, respectively. A minimum of three solutions are required to evaluate the convergence. The subscript $k$ refers to the $k^{\text {th }}$ input parameter (i.e. grid-size or time-step) (Stern et al. 2006)

Four different types of convergence and divergence conditions are possible: (i) monotonic convergence $(0<R<1)$, (ii) oscillatory convergence $(R<0 ;|R|<1)$, (iii) monotonic divergence $(R>1)$, and (iv) oscillatory divergence $(R<0 ;|R|>1)$ (Stern et al. 2006)

Table 4 presents the results of uncertainty analysis for heave and pitch transfer functions and added resistance coefficient. Grid uncertainty test results in a monotonic convergence for all three variables. As shown in Table 4 , numerical uncertainties for $\mathrm{TF}_{3} \mathrm{TF}_{5}$ and $\mathrm{C}_{\mathrm{AW}}$ are predicted as $3.21 \%, 2.52 \%$ and $3.02 \%$, respectively, based on the Grid Convergence Index (GCI) method.

Table 4 Grid Convergence Study for $\mathrm{TF}_{3} \mathrm{TF}_{5}$ and $\mathrm{C}_{\mathrm{AW}}$

\begin{tabular}{llll}
\hline & $\mathbf{T F}_{3}$ & TF5 & $\mathbf{C}_{\text {AW }}$ \\
\hline S1 & 0.857 & 0.718 & 10.03 \\
\hline S2 & 0.871 & 0.725 & 10.25 \\
\hline S3 & 0.897 & 0.735 & 10.68 \\
\hline $\boldsymbol{R}$ & 0.538 & 0.7 & 0.511 \\
\hline GCIfine & $3.21 \%$ & $2.52 \%$ & $3.02 \%$ \\
\hline
\end{tabular}

\subsubsection{Numerical Prediction of Motions Responses and Added Resistance in Waves}

Firstly, the numerical results of the heave and pitch motion predictions are compared with the experimental data. Using the transfer functions to compute the response amplitude operators of heave and pitch, motions are calculated. Results from experiments, CFD and 3D Potential Flow (PF) based methods are presented in Figure 15 and Figure 15. It can be seen that CFD predictions agree better with experiments than potential theory based method. Potential flow based method significantly over predicts heave motion at moderate to long waves. Heave RAO is decreasing as $\lambda / \mathrm{L}$ decreases and in short waves it gets closer to zero value. In long waves, it becomes closer to one which means ship vertically moves as the value of the wave amplitude. As discussed by Hizir et al. (2019), in 3D PF method, forward speed corrections are applied to 
boundary conditions as well as to the (NK) approximation where the steady wave and unsteady wave interactions are linearized. NK approach is known to overestimate the heave and pitch motion responses when compared against the experimental data.

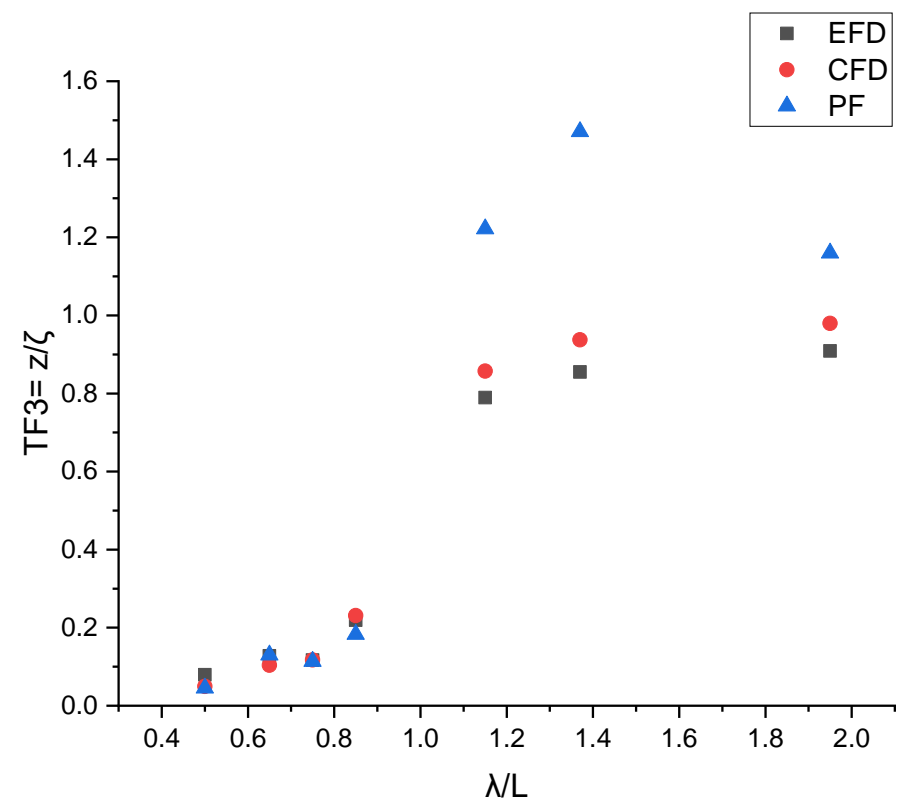

Figure 14 Comparison of computed and measured Heave motion RAOs

For pitch motion, CFD and EFD agree well except long wave region. The error increases as $\lambda / \mathrm{L}$ gets bigger than 1.15 . Pitch motion prediction with potential flow method showed good agreement with experiments and CFD calculations with slightly larger motion predictions at resonance period $(1.0<\lambda / \mathrm{L}<1.4)$ 


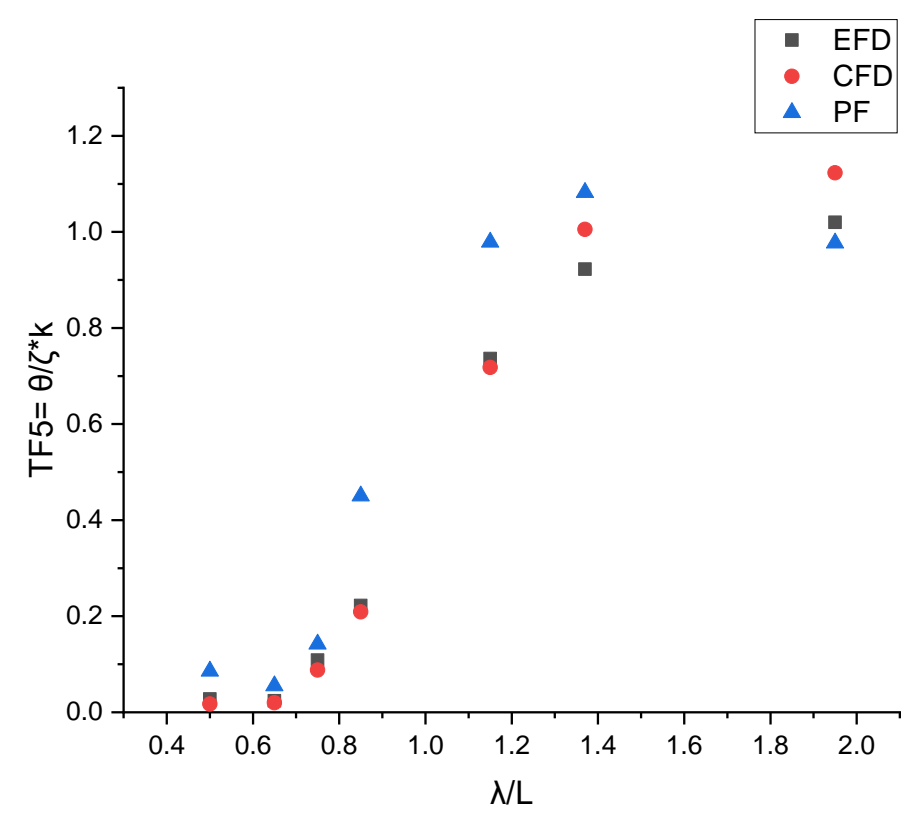

Figure 15 Comparison of computed and measured Pitch motion RAOs

Numerical results for the added resistance coefficient at level trim has been compared with EFD measurement of KHL as well as of FORCE (Simonsen et al. 2014) which conducted experiments for $6.1 \mathrm{~m}$ model of KCS for same range of $\lambda / \mathrm{L}$ and presented in

Figure 16. Overall trends are same for EFD, CFD and PF based methods. Discrepancies between linear potential theory and CFD are larger especially at short waves due to intensified non-linear hydrodynamics effects (Kashiwagi et al., 2010). 


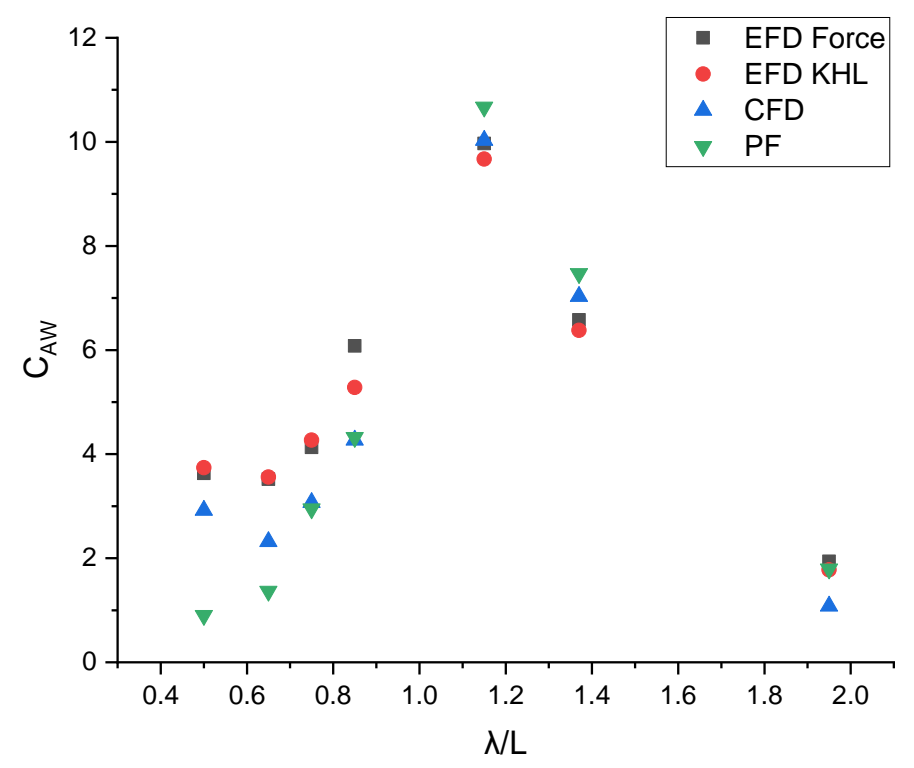

Figure 16 Comparison of CFD, PF and experimental data for added resistance coefficient in head waves for different wavelength conditions

As can be seen from

Figure 16 and Table 5, CFD agrees better with EFD when compared to PF for all trim angles. Both numerical methods under-predict the added resistance coefficients compared to the EFD data except at resonance period $(1.0<\lambda / \mathrm{L}<1.4)$. As viscosity cannot be included in 3-D potential flow theory method, ship motions and added resistance are over predicted around the resonant frequency region. As discussed earlier, over estimation of heave and pitch motion can be the contributing factor to over estimation of added resistance in this region. Results also show that there is a tendency for the prediction errors for added resistance coefficient to increase with increasing trim angle. It is possible to say that, CFD simulation results agree well with the experimental data for all trim angles considering the highly non-linear nature of seakeeping analysis.

Table 5 Prediction errors of added resistance coefficient for trim by bow conditions for CFD and PF simulations

\begin{tabular}{|c|c|c|c|c|c|c|c|c|c|c|c|c|}
\hline & \multicolumn{3}{|c|}{ CAw Level Trim } & \multicolumn{3}{|c|}{$\begin{array}{c}\mathrm{C}_{\mathrm{AW}} \text { 0.25 Deg trim by } \\
\text { bow }\end{array}$} & \multicolumn{3}{|c|}{$\begin{array}{c}\text { C }_{\text {AW }} 0.6 \text { Deg trim by } \\
\text { bow }\end{array}$} & \multicolumn{3}{|c|}{$\begin{array}{c}\text { CAw } 1 \text { Deg trim by } \\
\text { bow }\end{array}$} \\
\hline$\lambda / \mathbf{L}$ & $\begin{array}{l}\text { EFD } \\
\text { KHL }\end{array}$ & $\begin{array}{l}\text { CFD } \\
\text { E\%D }\end{array}$ & $\begin{array}{c}\text { PF } \\
\text { E\%D }\end{array}$ & $\begin{array}{l}\text { EFD } \\
\text { KHL }\end{array}$ & $\begin{array}{l}\text { CFD } \\
\text { E\%D }\end{array}$ & $\begin{array}{c}\text { PF } \\
\text { E\%D }\end{array}$ & $\begin{array}{l}\text { EFD } \\
\text { KHL }\end{array}$ & $\begin{array}{l}\text { CFD } \\
\text { E\%D }\end{array}$ & $\begin{array}{c}\text { PF } \\
\text { E\%D }\end{array}$ & $\begin{array}{l}\text { EFD } \\
\text { KHL }\end{array}$ & $\begin{array}{l}\text { CFD } \\
\text { E\%D }\end{array}$ & $\begin{array}{c}\text { PF } \\
\text { E\%D }\end{array}$ \\
\hline 0.5 & 3.87 & -18.36 & -33.00 & 3.68 & -15.48 & -31.84 & 3.81 & -16.23 & -48.61 & 3.79 & -16.58 & -58.79 \\
\hline 0.65 & 4.44 & -19.60 & -37.39 & 4.31 & -20.24 & -39.60 & 4.31 & -19.99 & -41.91 & 4.87 & -14.94 & -57.47 \\
\hline 0.75 & 4.57 & -16.04 & -31.13 & 4.41 & -16.85 & -29.31 & 4.24 & -12.48 & -19.33 & 4.82 & -11.50 & -36.79 \\
\hline
\end{tabular}




\begin{tabular}{|c|ccc|ccc|ccc|ccc|}
$\mathbf{0 . 8 5}$ & 5.32 & -14.04 & -17.24 & 5.30 & -13.78 & -19.73 & 5.56 & -16.90 & -11.31 & 5.01 & -11.70 & -21.09 \\
$\mathbf{1 . 1 5}$ & 9.78 & 2.59 & 9.14 & 9.94 & 0.45 & 5.28 & 9.79 & 1.41 & 6.42 & 9.76 & 2.32 & 4.22 \\
$\mathbf{1 . 3 7}$ & 6.37 & 9.65 & 18.14 & 6.64 & 4.49 & 9.69 & 6.63 & 5.24 & 6.86 & 6.98 & 3.80 & 4.40 \\
$\mathbf{1 . 9 5}$ & 1.78 & -4.95 & -3.26 & 1.83 & -11.93 & -11.28 & 1.90 & -9.89 & -14.72 & 1.74 & -5.40 & -7.12 \\
\hline
\end{tabular}

Table 6 Prediction errors of added resistance coefficient for trim by aft conditions for CFD and PF simulations

\begin{tabular}{|c|c|c|c|c|c|c|c|c|c|c|c|c|}
\hline \multirow[b]{2}{*}{$\lambda / \mathbf{L}$} & \multicolumn{3}{|c|}{ Caw Level Trim } & \multicolumn{3}{|c|}{$\begin{array}{c}\mathrm{C}_{\mathrm{AW}} 0.25 \text { Deg trim by } \\
\text { aft }\end{array}$} & \multicolumn{3}{|c|}{$\begin{array}{c}\mathrm{C}_{\mathrm{AW}} \text { 0.6 Deg trim by } \\
\text { aft }\end{array}$} & \multicolumn{3}{|c|}{$\mathrm{C}_{\mathrm{AW}} 1 \mathrm{Deg}$ trim by aft } \\
\hline & $\begin{array}{l}\text { EFD } \\
\text { KHL }\end{array}$ & $\begin{array}{l}\text { CFD } \\
\text { E\%D }\end{array}$ & $\begin{array}{c}\text { PF } \\
\text { E\%D }\end{array}$ & $\begin{array}{l}\text { EFD } \\
\text { KHL }\end{array}$ & $\begin{array}{l}\text { CFD } \\
\text { E\%D }\end{array}$ & $\begin{array}{c}\text { PF } \\
\text { E\%D }\end{array}$ & $\begin{array}{l}\text { EFD } \\
\text { KHL }\end{array}$ & $\begin{array}{l}\text { CFD } \\
\text { E\%D }\end{array}$ & $\begin{array}{c}\text { PF } \\
\text { E\%D }\end{array}$ & $\begin{array}{l}\text { EFD } \\
\text { KHL }\end{array}$ & $\begin{array}{l}\text { CFD } \\
\text { E\%D }\end{array}$ & $\begin{array}{c}\text { PF } \\
\text { E\%D }\end{array}$ \\
\hline 0.5 & 3.87 & -18.36 & -33.00 & 5.01 & -19.21 & -59.09 & 5.63 & -25.53 & -67.02 & 5.20 & -29.08 & -74.42 \\
\hline 0.65 & 4.44 & -19.60 & -37.39 & 5.30 & -19.92 & -54.13 & 5.58 & -23.45 & -60.08 & 5.22 & -23.80 & -67.70 \\
\hline 0.75 & 4.57 & -16.04 & -31.13 & 5.34 & -18.84 & -38.18 & 5.60 & -18.43 & -45.02 & 5.35 & -10.71 & -48.07 \\
\hline 0.85 & 5.32 & -14.04 & -17.24 & 6.24 & -19.04 & -24.78 & 6.25 & -18.09 & -23.86 & 5.90 & -17.17 & -28.18 \\
\hline 1.15 & 9.78 & 2.59 & 9.14 & 10.10 & 0.45 & 6.39 & 9.98 & 1.86 & 6.37 & 10.20 & -1.75 & -13.91 \\
\hline 1.37 & 6.37 & 9.65 & 18.14 & 6.78 & 6.04 & 10.70 & 7.75 & -5.68 & -5.16 & 6.99 & 6.66 & -17.70 \\
\hline 1.95 & 1.78 & -4.95 & -3.26 & 1.97 & -9.57 & -17.37 & 2.18 & -13.38 & -33.66 & 2.11 & -8.62 & -38.96 \\
\hline
\end{tabular}

When the ship is trimmed, position of the bulbous bow and transom have an impact on ships resistance. This effect is especially significant when bulbous bow partially come out of the water or transom stern partially immersed in water due to trim. As discussed by Kim et al. (2017), added resistance and relative wave height at bow section have a strong correlation between them. This also proves the importance of bow effect on added resistance. When the ship motions are maximum at around the resonance period, trim by bow cause an increase in the added resistance. One should also consider the bottom surface contribution to added resistance. The bottom surface does not contribute to the added resistance at even keel condition as the directional normal has zero component in longitudinal direction. Under trimmed conditions, these inclined bottom starts to contribute to added resistance. Another point is the evaluation of non-linear effects. As can be seen in Table 6 prediction errors for PF method is increasing with the increase in trim by aft. As trim angle increases, the draft at bow becomes smaller and bulbous bow shape changes. Thus, non-linear effects become more significant. While CFD can capture these non-linear effects better, prediction errors of added resistance by PF method increase especially when the trim angle is bigger. One can say that rapid linear potential flow calculations may not be suitable to predict the added resistance at large trim angles where keel contribution non-linearities are more significant. 


\subsection{Increase in the effective power of the vessel due to added resistance at different trim angles}

One of the most important considerations of energy-efficient shipping operations is to determine the power requirement of a ship at adverse operating conditions. A ship with higher power requirement will automatically require more amounts of fuel during the voyage, which will increase the fuel costs and carbon emissions.

The effective power $\left(\mathrm{P}_{\mathrm{E}}\right)$ is the power required to move the ship through the seaway at a given speed. It is calculated as the product of the total resistance of the ship and ship speed. As the speed is constant, the difference between total resistance coefficients between wave and calm water conditions are considered and calculations can be performed for each trim angle similar to the equation that was used by Tezdogan et al. (2015) as given below.

$\%$ Increase in $\mathrm{P}_{E}$ due to added resistance $=\frac{\Delta C_{T}}{C_{T, \text { calm }}} \times 100=\frac{C_{T, \text { wave }}-C_{T, \text { calm }}}{C_{T, \text { calm }}} \times 100$

Experimental predictions of the total resistance coefficients were applied to Eq. 9 and percentage increase in the effective power of KCS due to induced added resistance at different trim angles were obtained. Figure 17 and Figure 18 below present the obtained results comparing level trim predictions against trim by bow and trim by aft, respectively.

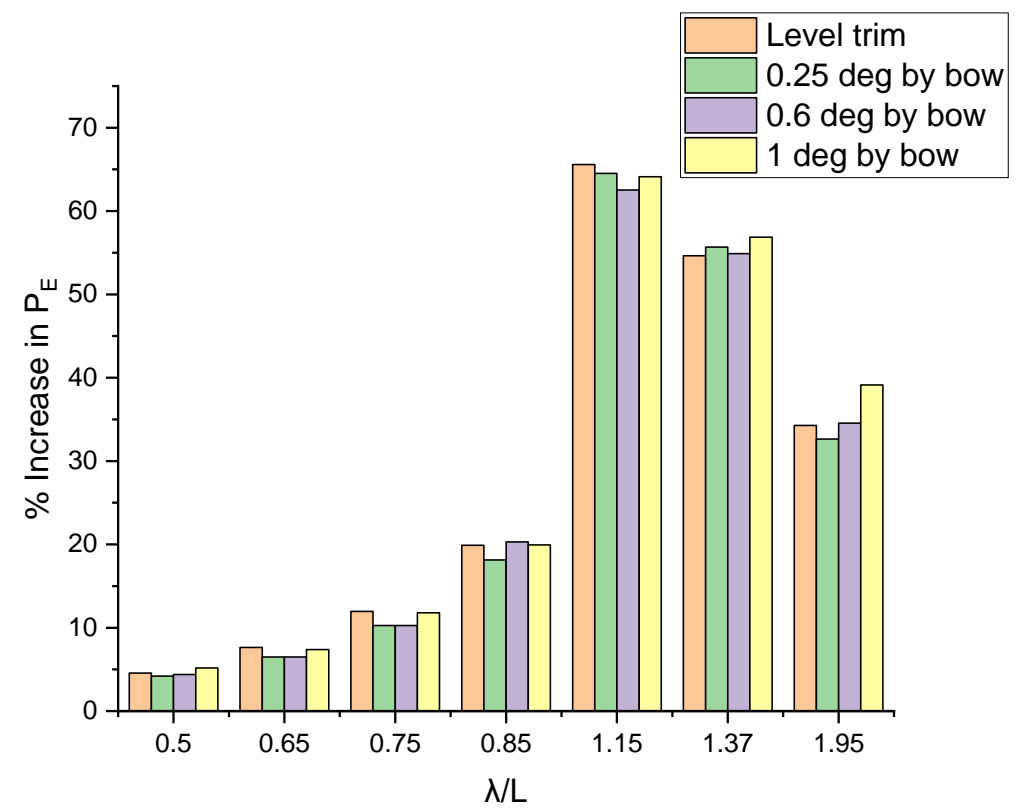

Figure 17 Percentage increase in effective power due to added resistance at different trim angles (Trim by bow) 
In short waves, small and moderate trim by bow results in the lowest increase in the effective power. The trend is similar to still water but it can be seen that 0.6 degrees trim by bow performs better in waves as it results in lower increase in effective power than level trim for almost entire wave conditions. Around the resonant period, moderate bow trim showed lower increase in power compared to low bow trim case. This is due to the combined effect of higher calm water resistance and slight reduction on ship motions at moderate trim when compared to low bow trim.

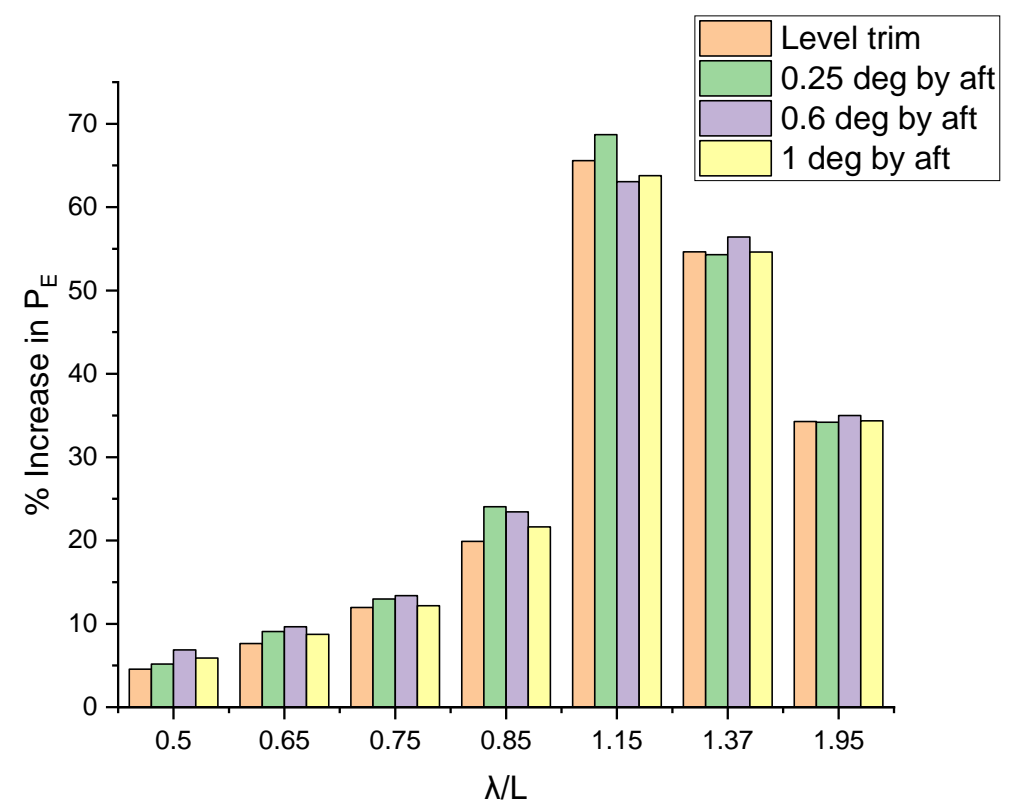

Figure 18 Effective power increase due to added resistance at different trim angles (Trim by aft)

Figure 18 show that trim by aft increase effective power requirement especially in short wave region. Highest increase in effective power for all trim angles is observed at $\lambda / L=1.15$ which is the resonance point. Compared to level trim operating condition, increase in effective power in trim by aft conditions is slightly larger. These trends can be observed for all the wave range. Therefore, it is possible to say that level trim operation performs better compared to operating at trimmed by aft condition.

\section{Conclusions}

In this study, experiments and numerical simulations were performed for bare hull KCS in regular head waves at different trim angles. Effects of trim on the added resistance and ship motions (heave and pitch) in regular head waves were investigated. Numerical results from the 
unsteady RANS and the 3-D potential flow method simulations were compared with experimental data for a broad range of wave conditions at different trim angles.

In the experimental results, it was shown that the trends for added resistance at different trim angles are close to the calm water ones in short wave region. Although the optimum trim trends at calm water and waves are similar for short waves, in long waves optimum trim angle trends are not always the same with calm water results. It was also demonstrated that operating at different trim angles have little influence on ship motions and that trend of ship motions are similar to operating at level trim especially in short wave region. Motion responses increase slightly in long wave region at bigger trim angles.

In the numerical analysis part, initially discretization errors were investigated to identify the optimum mesh structure for CFD analysis. After validating added resistance and heave and pitch motions with experimental data, computations and measurements correlated favourably. Motion response comparison for heave and pitch motions showed good agreement with experimental data. Added resistance coefficient was calculated for all trim angles and compared with experimental data. Both CFD and PF methods under-predict the added resistance coefficients compared to the EFD data except at resonance period $(1.0<\lambda / \mathrm{L}<1.4)$

Potential flow method can be applied in moderate wave range for small trim angles to achieve a quick estimation of the added resistance of ships at different trim angles in regular waves. In larger trim angles by aft and bow, however, potential flow method provided poor results for the prediction of added resistance. Thus, this method may not be suitable for computing added resistance in various trim angles.

Prediction wave added resistance and added power is still challenging for researchers and the industry. Although CFD methods can capture more relevant physics than traditional potential flow methods, improved accuracy may be costly as CFD simulations require powerful computers and are time-consuming. Especially short wave simulations are more computationally expensive than the long wave simulations due to high number of cells required to resolve the wave pattern at the free surface. With increasing High Performance Computing (HPC) capacity and access, CFD methods can provide a very useful tool to compare vessel performance at different trim angles and define optimum trim at both calm water and waves. In each case, a balance between available resources and required accuracy has to be found.

Traditionally hull forms are optimised at single point i.e. level trim at full load condition. Moving from single point optimisation to multi point optimization involves considering 
resistance and added resistance at different trim angles at different loading conditions. In this way, considerably improved fuel efficiency and reduced gas emissions can be achieved throughout the vessel's operational life. Effect of operating the ship at different trim angles should be considered during the ship design process. In performance monitoring, not only added resistance but also added power should be considered. In this respect, the future study should be extended to include a rotating propeller to investigate the effect of trim on propulsive performance in a seaway. Another interesting future study will be the extension of the numerical study to full scale in order to investigate scale effects on optimum trim angle.

\section{Acknowledgements}

Experimental results were obtained at the Kelvin Hydrodynamics Lab at the University of Strathclyde. Numerical results were obtained using the ARCHIE-WeSt High Performance Computer (www.archie-west.ac.uk) based at the University of Strathclyde.

\begin{tabular}{|c|c|c|c|}
\hline \multicolumn{4}{|c|}{ Nomenclature } \\
\hline$B_{W L}$ & Beam at waterline & $P F$ & Potential Flow \\
\hline $\mathrm{C}_{\mathrm{AW}}$ & Added resistance coefficient & $R$ & Ratio between solution changes \\
\hline$C_{B}$ & Block coefficient & $R A O$ & Response amplitude operator \\
\hline CFD & Computational Fluid Dynamics & $S$ & Wetted surface area \\
\hline$C_{T}$ & Total resistance coefficient & $S_{1}$ & Numerical solution \\
\hline$D$ & Depth & $T$ & Design draft \\
\hline$D F B I$ & Dynamic Fluid Body Interaction & $T F_{3}$ & Heave motion amplitude \\
\hline$E F D$ & Experimental Fluid Dynamics & $T F_{5}$ & Pitch motion amplitude \\
\hline EEDI & Energy Efficiency Design Index & $U$ & design speed \\
\hline$F r$ & Froude number & URANS & $\begin{array}{l}\text { Unsteady Reynolds averaged } \\
\text { Navier-Stokes }\end{array}$ \\
\hline$F_{X}$ & Total drag & $V O F$ & Volume of Fluid \\
\hline GCI & Grid Convergence Index & $x_{31}$ & $\begin{array}{l}\text { first harmonic amplitude of heave } \\
\text { motion }\end{array}$ \\
\hline$H P C$ & High Performance Computing & $x_{51}$ & $\begin{array}{l}\text { first harmonic amplitude of pitch } \\
\text { motion }\end{array}$ \\
\hline$I M O$ & $\begin{array}{l}\text { International } \\
\text { Organisation }\end{array}$ & $Y+$ & dimensionless wall distance \\
\hline$k$ & Wave number & $\Delta$ & displacement \\
\hline$K C S$ & Kriso Container Ship & $\varepsilon_{21}$ & Change between solutions \\
\hline$K H L$ & Hydrodynamics & $\zeta_{I 1}$ & wave amplitude \\
\hline
\end{tabular}




\begin{tabular}{|llll|}
\hline$L_{B P}$ & Length between the perpendiculars & $\lambda$ & wavelength \\
$L C G$ & Longitudinal centre of gravity & $\rho$ & $\begin{array}{l}\text { Density of water } \\
\text { dynamic viscosity }\end{array}$ \\
$L V D T$ & Linear Variable Differential & $\mu$ & \\
& Transformers & & \\
MARPOL & The International Convention for & $\overline{u_{i}}$ & average velocity vector \\
& Prevention of Marine Pollution For & \\
& Ships) & & \\
$N K$ & Neumann-Kelvin & $\bar{\tau}_{i j}$ & mean stress tensor \\
$\mathrm{P}_{\mathrm{E}}$ & Effective power & $\bar{p}$ & mean Pressure \\
\hline
\end{tabular}

\section{References}

ABS, 2014. Ship Energy Efficiency Measures Advisory.

Bertram, V., 2016. Added Power in Waves - Time to Stop Lying (to Ourselves), in: 1st Hull Performance \& Insight Conference HullPIC 2016. pp. 5-14.

Bertram, V., 2014. Trim Optimisation - Don't blind me with science! Nav. Archit. 14-15.

Blok, J.J., 1993. The resistance increase of a ship in waves. Delft University of Technology.

Carrica, P.M., Wilson, R. V., Noack, R.W., Stern, F., 2007. Ship motions using single-phase level set with dynamic overset grids. Comput. Fluids 36, 1415-1433. https://doi.org/10.1016/j.compfluid.2007.01.007

Castiglione, T., Stern, F., Bova, S., Kandasamy, M., 2011. Numerical investigation of the seakeeping behavior of a catamaran advancing in regular head waves. Ocean Eng. 38, 1806-1822. https://doi.org/10.1016/j.oceaneng.2011.09.003

Enger, S., Peric, M., Peric, R., 2010. Simulation of flow around KCS-hull, in: Gothenburg 2010-A Workshop on Numerical Ship Hydrodynamics.

Faltinsen, O.M., Minsaas, K., Liapis, N., Skjørdal, S.O., 1980. Prediction of resistance and propulsion of a ship in a seaway, in: The 13th Symposium on Naval Hydrodynamics. pp. $505-529$.

Ferziger, J.H., Peric, M., 2002. Computational Methods for Fluid Dynamics (Third Edit.). Springer, Berlin.

Gerritsma, J., Beukelman, W., 1972. Analysis of the resistance increase in waves of a fast cargo 
ship 12. Int. Shipbuild. Prog. 19, 285-293. https://doi.org/10.3233/isp-1972-1921701

Hansen, H., Freund, M., 2010. Assistance tools for operational fuel efficiency, in: 9th International Conference on Computer and IT Applications in the Maritime Industries, COMPIT 2010. Gubbio, Italy, pp. 356-366.

Hizir, O., Kim, M., Turan, O., Day, A., Incecik, A., Lee, Y., 2019. Numerical studies on nonlinearity of added resistance and ship motions of KVLCC2 in short and long waves. Int. J. Nav. Archit. Ocean Eng. 11, 143-153. https://doi.org/10.1016/j.ijnaoe.2018.02.015

HSH Nordbank, 2013. Expert Market Survey: Eco-Shipping.

Iakovatos, M.., Liaropakis, D.E., Tzabiras, G.D., 2014. Experimental investigation of the trim influence on the resistance characteristics of five ship models. Dev. Marit. Transp. Exploit. Sea Resour.

IMO, 2019. Technical and methodological issues related to the Fourth IMO GHG Study.

IMO, 2016a. GUIDELINES FOR THE DEVELOPMENT OF A SHIP ENERGY EFFICIENCY MANAGEMENT PLAN (SEEMP). MEPC.282(70) 9, 10. https://doi.org/10.5151/cidi2017-060

IMO, 2016b. EE Appraisal Tool for IMO Project report 45.

Joncquez, S.A.G., Bingham, H., Andersen, P., 2008. Validation of added resistance computations by a potential flow boundary element method, in: Proceedings of the 27th Symposium on Naval Hydrodynamics, Seoul Korea.

Joosen, W.P., 1966. Added resistance in waves., in: 6th Symposium on Naval Hydrodynamics. pp. 1-7.

Kashiwagi, M., Ikeda, T., Sasakawa, T., 2010. Effects of forward speed of a ship on added resistance in waves. Int. J. Offshore Polar Eng. 20, 196-203.

Kim, K.-H., Kim, Y., 2011. Numerical study on added resistance of ships by using a timedomain Rankine panel method. Ocean Eng. 38, 1357-1367.

Kim, M., Hizir, O., Turan, O., Incecik, A., 2017. Numerical studies on added resistance and motions of KVLCC2 in head seas for various ship speeds. Ocean Eng. 140, 466-476. https://doi.org/10.1016/j.oceaneng.2017.06.019

Larsen, N.L., 2011. Understanding the physics of trim 1-10. 
https://doi.org/10.1051/eas/1152023

Lewis, E.V., 1988. Principles of naval architecture second revision, volume III motions in waves and controllability. Soc. Nav. Arch. Mar. Eng.

Lv, X., Wu, X., Sun, J., Tu, H., 2013. Trim optimization of ship by a potential-based panel method. Adv. Mech. Eng. 2013. https://doi.org/10.1155/2013/378140

Maruo, H., 1957. The excess resistance of a ship in rough seas. Int. Shipbuild. Prog. 4, 337345. https://doi.org/10.3233/isp-1957-43501

Muzaferija, S., Peric, M., 1999. Computation of Free-surface Flows Using Interface- tracking and Interface-capturing Methods., in: Computational Mechanics Publications.

Newman, J.N., 1967. The drift force and moment on ships in waves. J. Sh. Res. 11, 51-60.

Orihara, H., Miyata, H., 2003. Evaluation of added resistance in regular incident waves by computational fluid dynamics motion simulation using overlapping grid system. J. Mar. Sci. Technol. 8, 47-60. https://doi.org/10.1007/s00773-003-0163-5

Park, D.M., Kim, Y., Seo, M.G., Lee, J., 2016. Study on added resistance of a tanker in head waves at different drafts. Ocean Eng. 111, 569-581. https://doi.org/10.1016/j.oceaneng.2015.11.026

Roache, P.J., 1998. Verification and Validation in Computational Science and Engineering.

Salvesen, N., 1978. Added Resistance of Ships in Waves. J. Hydronautics 12, 24-34. https://doi.org/https://doi.org/10.2514/3.63110

Salvesen, N., Tuck, E.O., Faltinsen, O., 1970. Ship Motion and Sea Loads.pdf, in: SNAME Trans 78.

Sato, Y., Miyata, H., Sato, T., 1999. CFD simulation of 3-dimensional motion of a ship in waves: application to an advancing ship in regular heading waves. J. Mar. Sci. Technol. 4, 108-116. https://doi.org/10.1007/s007730050013

Shivachev, E., Khorasanchi, M., Day, A.H., 2017. Trim Influence on Kriso Container Ship (KCS); An Experimental And Numerical Study, in: Proceedings of the ASME 2017 36th International Conference on Ocean, Offshore and Arctic Engineering. Trondheim, pp. 17.

SIEMENS, 2017. User guide STAR-CCM+ Version 12.06.010-R8. 
Sigmund, S., el Moctar, O., 2018. Numerical and experimental investigation of added resistance of different ship types in short and long waves. Ocean Eng. 147, 51-67. https://doi.org/10.1016/j.oceaneng.2017.10.010

SIMMAN, 2008. MOERI Container Ship (KCS) Geometry and Conditions [WWW Document]. http://www.simman2008.dk/KCS/kcs_geometry.htm.

Simonsen, C.D., Otzen, J.F., Joncquez, S., Stern, F., 2013. EFD and CFD for KCS heaving and pitching in regular head waves. J. Mar. Sci. Technol. 18, 435-459. https://doi.org/10.1007/s00773-013-0219-0

Simonsen, C.D., Otzen, J.F., Nielsen, C., Stern, F., 2014. CFD prediction of added resistance of the KCS in regular head and oblique waves, in: The 30th Symposium on Naval Hydrodynamics.

Stern, F., Wilson, R., Shao, J., 2006. Quantitative V\&V of CFD simulations and certification of CFD codes. Int. J. Numer. Methods Fluids 50, 1335-1355. https://doi.org/10.1002/fld.1090

Sun, J., Tu, H., Chen, Y., Xie, D., Zhou, J., 2016. A Study on Trim Optimization for a Container Ship Based on Effects due to Resistance. J. Sh. Res. 60, 30-47. https://doi.org/10.5957/josr.60.1.150022

Tezdogan, T., Demirel, Y.K., Kellett, P., Khorasanchi, M., Incecik, A., Turan, O., 2015. Fullscale unsteady RANS CFD simulations of ship behaviour and performance in head seas due to slow steaming. Ocean Eng. 97, 186-206. https://doi.org/10.1016/j.oceaneng.2015.01.011

UNCTAD, 2017. Review of Maritime Transport 2017. New York.

Van't Veer, 2009. PRECAL v6.5 Theory Manual.

Weymouth, G.D., Wilson, R.V., Stern, F., 2005. RANS computational fluid dynamics predictions of pitch and heave ship motions in head seas. J. Sh. Res. 49, 80-97. 